\title{
CAILLAMA: ORGANIZACIÓN DEL ESPACIO DOMÉSTICO Y ÁREAS DE ACTIVIDAD EN UN ASENTAMIENTO PREHISPÁNICO DE ALTURA, PERÍODO INTERMEDIO TARDÍO NORTE DE CHILE
}

\author{
CAILLAMA: DOMESTIC AREA ORGANIZATION \\ AND ACTIVITY ZONES IN A HIGHLAND LATE INTERMEDIATE \\ PERIOD SETTLEMENT IN NORTHERN CHILE
}

Iván Muñoz Ovalle ${ }^{1}$

\begin{abstract}
Este trabajo describe y discute la organización del espacio doméstico y las áreas de actividad en seis recintos del poblado de Caillama ${ }^{1}$, ubicado a $3.000 \mathrm{msm}$ en la sierra de Arica. Este es un asentamiento vinculado al período Intermedio Tardío (1.100 al 1.300 d.C.), de acuerdo a los estilos de cerámica. En la primera parte del trabajo se hace referencia a la problemática regional sobre el estudio arqueológico de asentamientos, se plantean algunos conceptos teóricos en torno a la identificación de áreas de actividad en sitios arqueológicos. En la segunda parte se describe el asentamiento de Caillama y las áreas de actividad que lo componen; con base en los materiales de los recintos excavados. Acompañan esta descripción el registro de cerámica como parte del equipo doméstico y el análisis de componentes químicos provenientes de muestras de suelos de los mismos recintos excavados.
\end{abstract}

Palabras claves: sistemas de asentamiento, áreas de actividades domésticas, análisis químicos de suelo, norte de Chile.

Domestic area organization and the activity zones are the focus of this study of six settlements from Caillama Village, which is situated at 3,000 m.a.s.l. in Arica's sierra. From a chronological point of view, based on pottery styles, settlements correspond to the Late Intermediate Period (1,100 to 1,300 A.D.). The first part of this work concentrates on regional settlement patterns using theoretical concepts relating to identifying domestic and specialized activity areas. The second part deals with evidence from Caillama Village and the activity zones that constitute it, with descriptions of areas excavated and materials discovered. This includes a description of the domestic pottery and results of chemical analyses of soil samples from excavated areas.

Key words: Settlement system, domestic areas of activities, chemical soil analyses, Northern Chile.

\section{Antecedentes Teóricos}

Según Florín (2001) el espacio doméstico constituye una unidad espacial en la cual un grupo social desarrolla su vida cotidiana. Rappaport (1990) y Middleton y Price (1996) señalan que la vida cotidiana correspondería a la suma de actividades que un grupo social realiza durante el día, es decir, un conjunto de hechos que expresan una experiencia social en movimiento. A diferencia del espacio doméstico el grupo territorial constituye un conjunto de grupos domésticos que ocupan y usufructúan un espacio determinado. Los espacios domésticos son ocupados por determinados grupos sociales, que se caracterizan por una serie de actividades y procesos en base de los cua- les el grupo se integra en la sociedad en una sucesión de niveles de complejidad e integración (Flannery 1976).

En cuanto a las áreas de actividad, Flannery (1976) introduce el concepto de feature que son las unidades analíticas específicas, es decir, una pequeña unidad de análisis como un fogón o depósito, evidencias que algunos autores como Barba (1991) ven como sinónimo de área de actividad, es decir, una unidad mínima del registro arqueológico con contenido social. El área de actividad definida por Barba y Manzanilla (1987:69) es "el reflejo en el registro arqueológico de una separación espacial a nivel funcional de las tareas cotidianas y de las conductas repetidas".

1 Departamento de Antropología, Universidad de Tarapacá, Arica, Chile. imunoz@uta.cl 
Manzanilla (1986) plantea que la organización interna del área de actividad es consecuencia de un aprovechamiento pautado del espacio, de actividades sociales particulares. Señala que estas áreas de actividad se pueden clasificar en producción, uso, consumo, almacenamiento y evacuación; y que el siguiente nivel correspondería a la unidad habitacional. Wilk y Ashmore (1988) por su parte plantean que la conformación de más de una unidad doméstica o household cluster correspondería a los niveles de integración de los distintos componentes sociales y agentes productivos determinados.

De lo anteriormente planteado pensamos que esta información será clave pues nos ayudará a entender cómo se articuló el espacio doméstico al interior de las viviendas de Caillama; pretendemos discutir las diferencias y similitudes de estos espacios, a través de los restos culturales, las actividades que se pudieron haber desarrollado a partir de los restos de los pisos de ocupación (análisis químico) y los objetos que se utilizaron en la vida cotidiana.

\section{La arqueología de asentamientos en los valles del área Centro Sur Andina}

Estas investigaciones han tenido distintos objetivos. La gran mayoría como los trabajos de Niemeyer et al. (1972/73) se han referido a la formación de los asentamientos, distribución de áreas y componentes arquitectónicos, otros, sin embargo, y tal vez los menos, a la distribución de los espacios funcionales al interior de los recintos y áreas de actividad, objetivo central de nuestro trabajo. Muñoz (2005:324-326) al hacer una recopilación sobre los estudios de asentamientos en el área Centro Sur Andina señala que éstos se han centrado principalmente en los valles de Moquegua, Lukurmata y sierra de Arica.

Haciendo un breve comentario sobre lo planteado diremos que en la cuenca de Osmore, Moquegua, Aldenderfer (1993) discutió la arquitectura doméstica, en relación con la etnicidad y complementariedad de los recursos; este estudio lo basó en relación al sitio arcaico de Asana mostrando un largo proceso de ocupaciones de dicho asentamiento. Por su parte Conrad (1993) al referirse a la arquitectura doméstica en la fase Estu- quiña y San Antonio señala un patrón semejante con las estructuras habitacionales de Chiribaya que desde el punto de vista arquitectónico serían más bien simples en su interior. En este mismo valle es interesante mencionar los trabajos de Goldstein (1989) en el sitio Omo, y Williams et al. (2001) en el sitio Cerro Baúl, asentamientos que si bien estuvieron vinculados a elites complejas tanto de Tiwanaku como de Wari, en cuya arquitectura observamos plataformas escalonadas, recintos para funciones ceremoniales y otros grandes para albergar familias y depositar la producción agrícola, también hay registros de recintos más pequeños, con un arquitectura simple, los que al parecer tuvieron la función de albergar a los agricultores del valle. Un caso similar lo vemos en los trabajos de Lukurmata en el área de Tiwanaku; por un lado, hay descripciones como las de Kolata (1989) quien señala una serie de construcciones públicas y residencias para la elite y otras como las descritas por Stanish (1989:42) para una población no elitista más amplia, localizada en la periferia del asentamiento cuyos recintos son más simples. Un caso específico sobre el tipo de residencia para los períodos III (200-500 d.C.) y IV (500-900 d.C.) lo señalan Bermann y Graffman (1989), quienes al comparar las casas 2 y 7 observan diferencias: la casa 2 corresponde a una estructura de forma oblonga irregular con un tamaño de 2 x $4 \mathrm{~m}$ con un poste central, se hallaron tres fogones. La casa 7 es una estructura circular de $3 \mathrm{~m}$ de diámetro, se halló un solo fogón.

Respecto a Tiwanaku, Janusek (2001:257) señala que la actividad diaria como alimentarse, educar a los niños y dormir se hizo en los mismos centros ceremoniales; esto demostraría que Tiwanaku fue un sitio dinámico donde la vida doméstica estuvo ligada a una gran convergencia social y ceremonial. Un ejemplo de esta convergencia se refleja en Akapana Este 1 y 2, allí la actividad doméstica se registra en las basuras dejadas en los patios externos donde se prepararon y consumieron los alimentos, desollaron camélidos, guardaron alimentos secos y líquidos en recipientes. Las actividades de cocina están documentadas por fogones, combustible, hornos, ollas y tinajas. Junto a estos registros domésticos se hallaron implementos de hueso y piedra, sahumadores hechos en cerámica, entierros de fetos de camélidos y entie- 
rros humanos depositados en los pisos y muros de las áreas residenciales, lo cual demuestra paralelamente un uso ceremonial de los espacios residenciales.

Esta complejidad social de los asentamientos de Tiwanaku y Wari aparentemente desaparece en el período Pacaje Temprano. Albarracín y Mathews (1990:140) al referirse al patrón de asentamiento de este período (1.100-1.470 d.C.) plantean la emergencia de una proliferación de sitios similares a los encontrados en la sierra de Arica durante el mismo periodo. Esta red de asentamientos sería consecuencia de la culminación del proceso de fragmentación que se inició durante la última fase del período Tiwanaku V.

En relación a la sierra de Arica, Muñoz y Chacama (2006), tomando como indicador la arquitectura del período Intermedio Tardío, describen una serie de sitios que se distribuyen desde el norte por la quebrada de Socoroma hasta el sur por la quebrada de Miñita. Estos autores señalan que estos asentamientos se planificaron en torno a cinco áreas: (1) habitacional, que abarcó desde la mitad de la ladera hasta la cima; (2) depósito, que se distribuyó espacialmente como una unidad, entre el área residencial y la de corrales ubicados en el centro y sector bajo de laderas; (3) funeraria, que se situó en espacios separados de las áreas habitacional y de depósito, por lo general en las cimas o a media ladera de cerros por sobre las áreas domésticas; (4) corrales, que se ubicaron preferentemente en los faldeos de ladera, cercanos a las áreas de depósito de almacenaje; y (5) sistemas agrícolas, los que se ubican en los cerros que circundan los poblados. Esta planificación al parecer obedeció a un sistema estratégico como respuesta a un estadio de pugnas interétnicas por intereses productivos entre las poblaciones altiplánicas y costeras. La presencia de grandes lascas, boleadoras, bifaces, con uno de sus extremos aguzado, por lo general hallados en la cima de los sitios, sugiere que estos instrumentos probablemente sirvieron como objetos de defensa (Muñoz y Chacama 2006:143-144).

En cuanto a las características arquitectónicas generales de estas áreas, Muñoz y Chacama (2006) señalan que el área habitacional presenta recintos de forma circular, a su vez el área de depósito o almacenamiento se caracteriza por dos tipos de construcciones: depósitos circulares pequeños, vinculados a las viviendas propiamente tales, y otros de tamaño mayor, construidos sobre la superficie y ubicados en determinados espacios de los poblados, posiblemente asociados a depósitos comunales. El área funeraria se caracteriza por dos tipos de tumbas, una de forma de cista, cavada en el piso, y otra tipo chullpa, elaborada con barro y paja. Ambos tipos de sepulturas se presentan muy disturbadas, muchas de ellas sin restos óseos. El área de corrales se caracteriza por grandes recintos construidos con una sola hilera de piedras, ubicados en la base de laderas de cerros. Los sistemas agrícolas están definidos por terrazas, construidas en las laderas de los cerros, presentando en su interior extensos canales longitudinales que alimentan a canales más pequeños que se distribuyen en forma vertical. En relación con Caillama, Muñoz y Chacama (2006) lo describen como un asentamiento tipo pukara, según la definición de Ruiz y Albeck (1997), es decir, asentamientos elevados, protegidos y de acceso difícil, con gran visibilidad de su entorno.

En este breve análisis observamos que los asentamientos más representativos del área centro sur andina ubicados en el área nuclear circumtiticaca presentan diversas funciones, así como una estructura monumental. En ellos se concentró una gran población con distintos niveles estratigráficos. En cambio, en la sierra de los valles occidentales como el caso de Arica hallamos durante el período Intermedio Tardío poblaciones de agricultores que edificaron sus asentamientos en espacios estratégicos de altura, cuyas viviendas se hallan nucleadas, con un pasillo central que vinculaba los distintos espacios ocupacionales, sin grandes diferencias arquitectónicas entre ellos, y que estuvieron comunicados entre sí bajo una extensa red vial.

\section{Hipótesis, Objetivos y Metodología}

Las áreas domésticas representadas por una variedad de evidencias materiales en el interior de las viviendas del asentamiento de Caillama son testimonios de las actividades de subsistencia, protección e interacción social que se llevaron a cabo en dicho asentamiento, a su vez, su materialidad dejada como testimonio de estas actividades ex- 
presaría el sentido de identidad y pertenencia del grupo familiar que habitó dichos espacios. Teniendo presentes ambas hipótesis, el objetivo de esta investigación fue reconstruir el espacio social doméstico generado al interior de los recintos habitacionales, para esto: (a) se estudió la arquitectura habitacional con el propósito de conocer aspectos constructivos, distribución del espacio interior, acceso, dimensión de los recintos, orientación, etc.; e inferir las características del grupo doméstico que los habitó; (b) se describieron los componentes culturales, especialmente la cerámica, para la identificación de los grupos que ocuparon estos espacios; (c) se determinaron, a través del análisis químico de muestras tomadas en los recintos excavados, elementos que pudieron corresponder a actividades humanas, tales como preparación y consumo de alimentos, lo cual nos ayudó a determinar la funcionalidad del espacio. Las muestras fueron tomadas de un solo estrato ocupacional que se extiende a lo largo de los recintos, cuyo espesor es de 5 a $7 \mathrm{~cm}$, ubicado sobre la roca madre. A su vez, está cubierto por un depósito superficial de color gris de textura arcillosa.

En cuanto a la metodología tomamos como unidades de referencia los recintos más representativos en términos de patrón arquitectónico y restos de ocupación doméstica que se observaban en la superficie de los recintos (Figura 1: Recintos $123,124,144,151,175$ y 197). Una vez definido el sistema constructivo de la vivienda, realizamos un registro visual del piso ocupacional interno, intentando detectar en superficie restos de muros, postes y techumbre que conformaron la estructura de la vivienda. Las excavaciones abarcaron la totalidad de la superficie interna de los recintos, lo que permitió definir los componentes estructurales de la vivienda y el material empleado en su construcción, así como una serie de componentes culturales (fogones, basurales, lineamientos de postes, morteros, etc.) relacionados con el consumo y preparación de alimentos (Figuras 2 y 3 ). Los espacios exteriores no fueron excavados, de tal manera que los contextos descritos en los espacios fuera de la vivienda corresponden a hallazgos superficiales.

Las áreas de actividad en el interior de los recintos se determinaron principalmente a través de los restos culturales, apoyados por el análisis químico de restos orgánicos; estos restos fueron tomados preferentemente de las áreas de alimentación y cocinas, que presentaban indicadores visibles de su funcionamiento. Las muestras recolectadas fueron de $150 \mathrm{gr}$. Respecto a las posibles áreas de descanso y almacenaje las muestras tomadas fueron muy bajas no alcanzando los $100 \mathrm{gr}$; la escasa densidad estratigráfica de los pisos de ocupación impidió una muestra mayor para una mejor determinación química de suelos. Para el análisis comparativo se realizó un muestreo de suelo no alterado, que sirvió como patrón de referencia (ver Muñoz et al. 2007). Con la información obtenida en los pisos de ocupación, los análisis de laboratorio siguieron el proceso establecido por Barba y Córdova (1999), para la determinación de fosfatos, carbonatos, $\mathrm{pH}$, residuos proteicos y ácidos grasos. Otros elementos como determinación de color, potencial de hidrógeno, calcio, hierro y albúmina, descritos por Barba y Ortiz (1992) considerados para el análisis de pisos de ocupación en viviendas etnográficas en Tlaxcala, México, no se consideraron, ya que el método utilizado por dichos autores fue propuesto para una vivienda etnográfica de la cual se conocía de antemano la funcionalidad de los distintos espacios. En el caso de nuestros recintos prehispánicos se consideró, como señaláramos anteriormente, aquellos espacios que presentaban indicadores visibles de funcionalidad como el caso de las cocinas, fogones y desechos; por otro lado, se concentraron los esfuerzos en las determinaciones químicas antes señaladas, pensando que este trabajo es una primera aproximación al aporte de los análisis químicos al proceso de identificación de los espacios funcionales llevado a cabo en registros arqueológicos en el extremo norte de Chile. En dicho contexto las determinaciones realizadas nos indican una aproximación en forma clara de diversas actividades domésticas llevadas a cabo en el espacio analizado. Finalmente el trabajo en laboratorio permitió generar una tabla de valores sobre los componentes y distribución de concentraciones químicas, lográndose establecer mapas de distribución. Mayores antecedentes sobre materiales y métodos, determinaciones, resultados y comentarios finales se pueden ver en Muñoz et al. (2007).

El estudio de la cerámica se basó en la muestra total de una cuadrícula por recinto excavada, en total seis; la descripción se realizó en función 


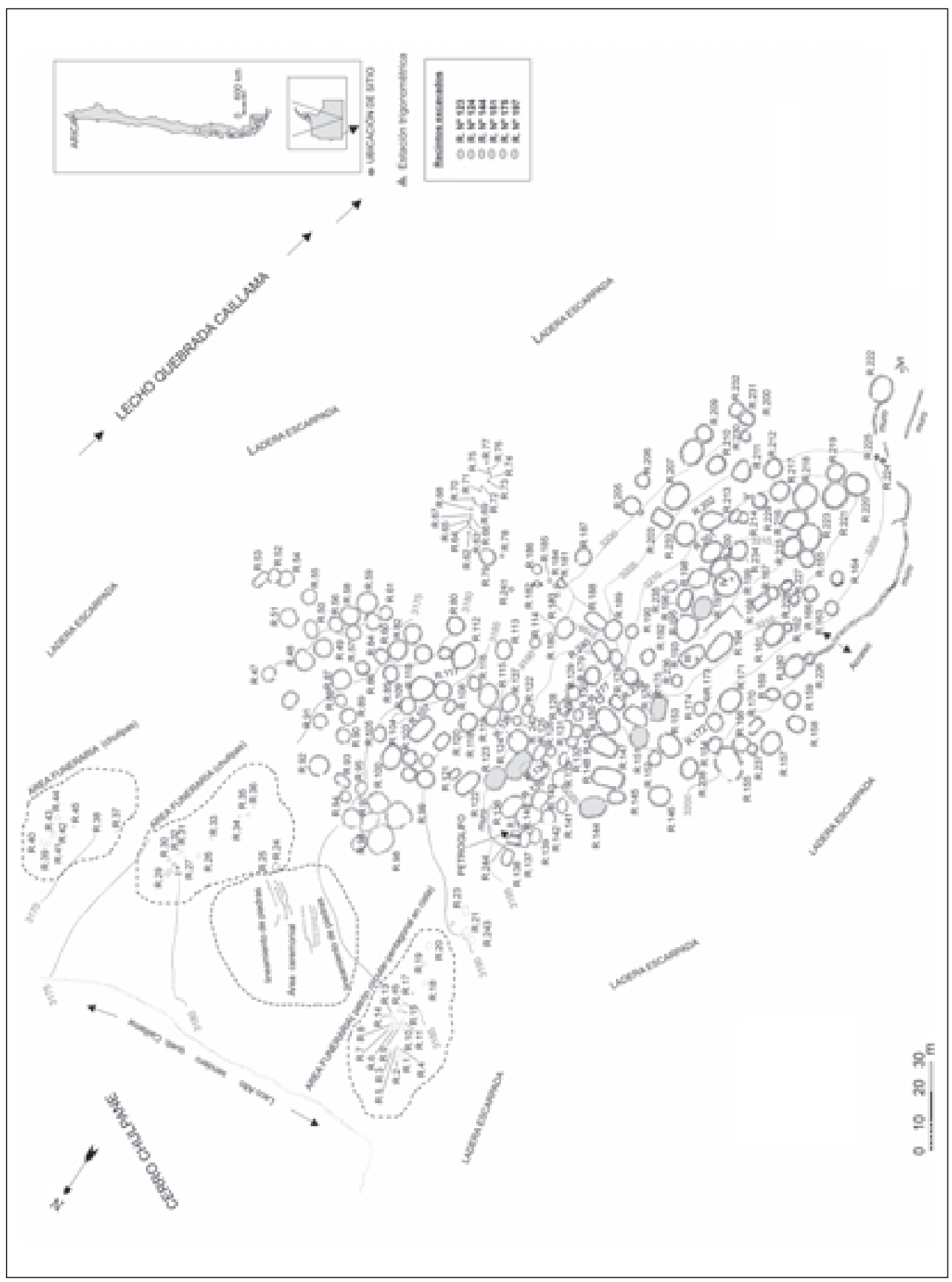

Figura1. Sitio Caillama.

Caillama site. 


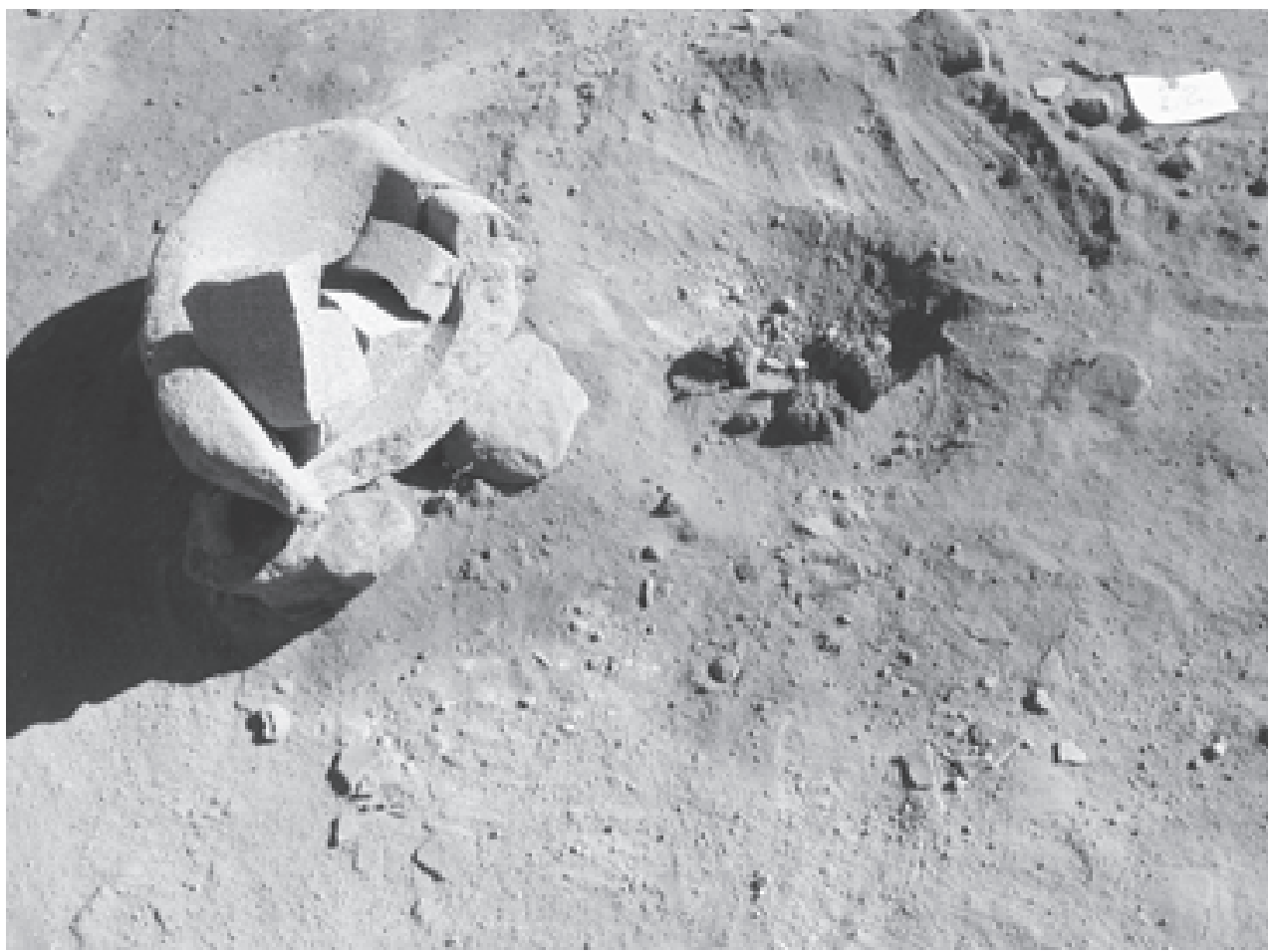

Figura 2. Detalle de mortero fragmentado y evidencia de postación recinto 151.

Fragmented mortar and evidence of a post in enclosure 151.

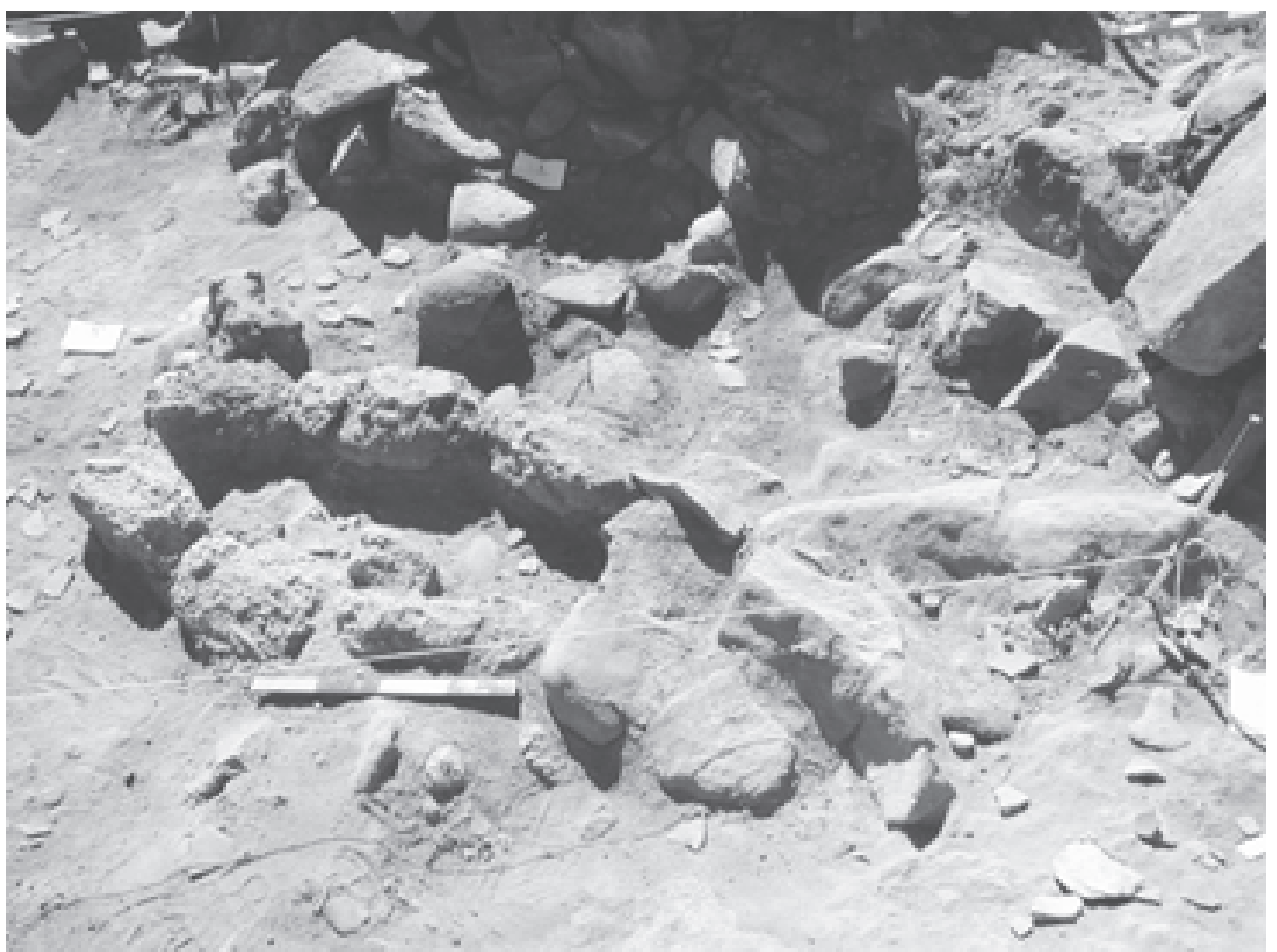

Figura 3. Restos de cocina adosada a muro, recinto 197.

Remains of hearth lean-to, enclosure 197. 
de las formas y estilos, aspectos que proporcionaron información fundamental sobre las formas de vasijas utilizadas, así como la decoración empleada en éstas. Como propuesta de análisis tomamos como referencia el trabajo realizado por Muñoz y Chacama (2006).

\section{El Asentamiento}

El sitio Caillama, por su estratégico emplazamiento y por la presencia de un muro perimetral, constituye lo que denominamos un pukara de cumbre (Figura 4), es decir, un sitio de carácter defensivo situado aisladamente sobre un promontorio central; en este caso el sitio está acompañado por un espacio ceremonial (sector externo) dedicado al culto a los ancestros a través de la construcción de chullpas. En una dimensión más amplia tal como lo plantean Muñoz y Chacama (2006:36) el pukara de Caillama en la quebrada de Chapiquiña debió haber interactuado con otros asentamientos como Laco Alto, situado inmediatamente al frente en los faldeos del cerro conocido como Elena Capurata, y el asentamiento de Pujone, ubicado aguas abajo sobre la margen norte de la quebrada de Chapiquiña. Este conjunto de sitios es atravesado por un sendero, ruta que permitió comunicarse con la sierra, $3.000 \mathrm{msm}$; y continuar hacia la quebrada de Livilcar, $1.600 \mathrm{msm}$, llegando a la costa del Pacífico vía valle de Azapa.

Internamente el sitio parece haber sido constituido tomando como centro de referencia el peñón central, en su alrededor se desplegó un conjunto de recintos de forma circular. En el frente noreste observamos una entrada que luego se convierte en pasillo central (Figura 5); este pasillo constituye la columna vertebral del poblado, presenta dos ramales, uno que va hacia la cima del poblado y otro que se dirige hacia los montículos que conforman el barranco. Los pasillos de circulación en el interior del poblado sugieren que el asentamiento fue levantado gradualmente siguiendo una idea preconcebida; de ser así, queda la posibilidad que el patrón de asentamiento privilegia una jerarquía concéntrica cuyo anillo más amplio lo constituye el muro perimetral que rodea al sitio. En este esquema, el acceso de un anillo a otro se dio a través de un umbral conformado por gra-

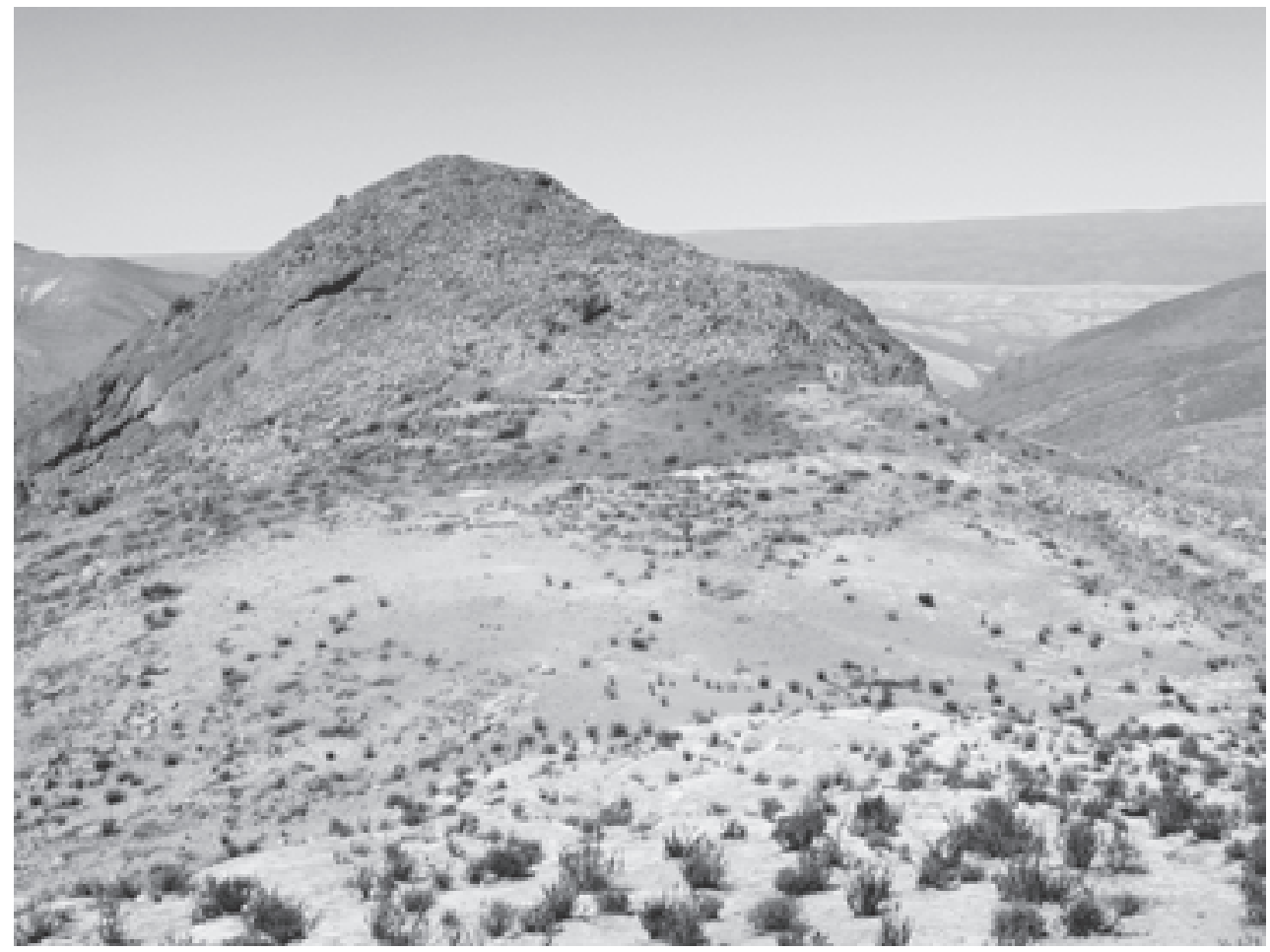

Figura 4. Vista panorámica de Caillama.

Panoramic view of Caillama. 


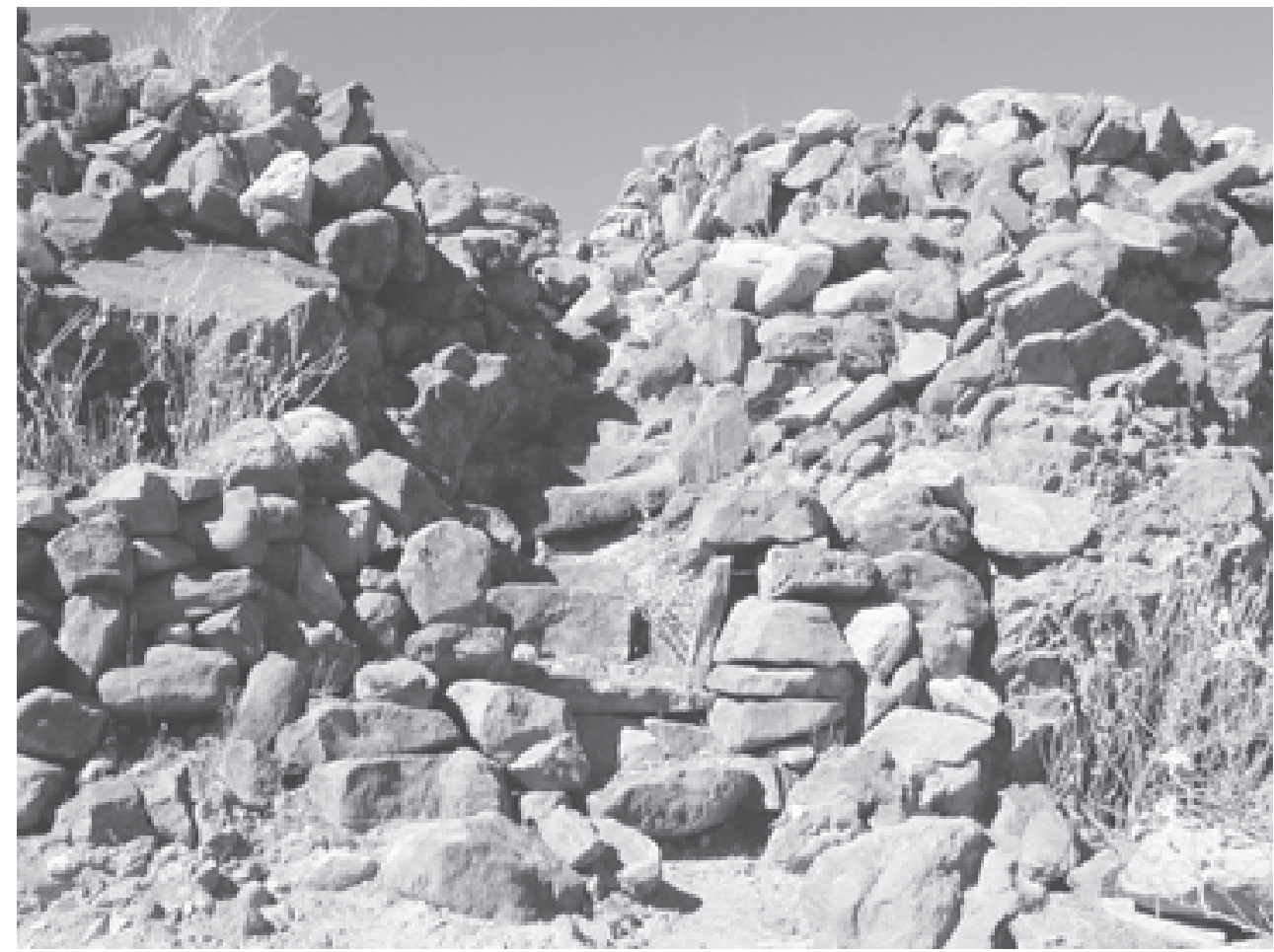

Figura 5. Pasillo central con peldaños conducentes a la cima del sitio.

Central corridor with useful steps to the top of the site.

das y grandes bloques que lo flanquean; el umbral superior podría incluso estar simbólicamente marcado por la presencia de una posible hornacina, que contendría un ídolo (piedra natural con forma de llama). La jerarquía de los anillos concéntricos se correspondería con la característica defensiva del sitio, en cuyo caso los sectores de mayor altura y por ende de más difícil acceso constituirían la parte más jerarquizada del sitio.

Sin embargo, a diferencia de estos anillos concéntricos que pudieron haber albergado estructuras de poder a partir de un mayor o menor número de recintos, los espacios domésticos al interior de los recintos presentan similitud, careciendo de elementos que jerarquicen unos de otros; no se observan diferencias significativas en lo que tiene que ver con las áreas de actividad que los caracterizan, lo que nos lleva a reflexionar en el sentido que las estructuras habitacionales no fueron un elemento que marcara diferencias de poder y condición social. Tal como plantea Blanton (1998), la igualdad de las viviendas pudo haber sido consecuencia del predominio de aspectos corporativos en la organización política, descansado en el con- trol de los medios de producción local mediante códigos cognitivos que enfatizaron la solidaridad entre unidades sociales. Nielsen (2001) señala que este tipo de organización no se construye a partir del engrandecimiento del individuo, a través de sus bienes materiales, sino en función de la solidaridad corporativa.

Quizás los mecanismos de jerarquía estuvieron en la construcción de las chullpas, que se caracterizan por 40 recintos funerarios diferenciados en dos tipos de edificaciones. El primer tipo corresponde al patrón circular-pentagonal, definidos como cistas semiaéreas (Romero 2003:90). El segundo tipo corresponde a edificios rectangulares, estructurados en barro y piedras lajas sobre terraplén; a pesar de su destrucción tres se hallan en mejor estado de conservación. Las cistas semi-aéreas se encuentran separadas del área de chullpas por un espacio al cual hemos denominado sector ceremonial, que está delimitado por lineamientos de piedras de curso irregular, cuyas longitudes fluctúan entre 40 y $50 \mathrm{~m}$.

Estas construcciones funerarias al parecer constituyeron un aspecto central en el orden polí- 
tico tal como lo postula Isbell (1996) para los Andes centrales. En Caillama pudieron haber surgido grupos corporativos en el control de la tierra y ayllu, los que fueron privilegiados a partir del ancestro fundador, en este caso, enterrados en sus chullpas. Sobre las chullpas de Caillama, Romero (2003) en relación a su función señala que éstas se relacionarían dentro de un esquema de complementariedad y diálogo ideológico entre los grupos serranos y las poblaciones de puna, lo cual les habría permitido alcanzar un equilibrio en las relaciones establecidas.

La información recopilada de las distintas áreas que conforman el poblado de Caillama sugiere que grupos asentados en este poblado parecen haber estado formados por familias nucleares. Tal como plantea Kent (1990), pudieron corresponder a un grupo formado por individuos unidos en su mayoría por parentesco biológico y ceremonial, estas familias con el tiempo fueron aumentando en número, puesto que sus hijos se iban casando, lo cual pudo conducir a un aumento de los recintos. La presencia de estructuras tipo unidades alveolares como las definidas por Lavallèe y Julien (1983) ha sido detectada en nuestro asentamiento a partir de un patio central, estas unidades que están sectorizadas a través de pasillos interiores hacen pensar que en Caillama pudieron haber existido grupos residenciales conformados por familias extensas. Algunas de estas unidades alveolares podrían corresponder a los recintos 56 al 61, 135 al 142; 105,193 al 201, 123 al 134, 165, 212, 215, 116, 217, 218 y 223.

En relación a cómo fue percibido el espacio social en Caillama nos inclinamos a pensar que este fue de manera integral; es difícil pensar que hayan percibido solamente la casa o el recinto, sino el conjunto de ellas formando una aldea, tal como lo plantean Caiuby et al. (1983) sobre registros etnográficos amazónicos. En estas sociedades nativas las actividades se dan en un espacio que es fundamentalmente integrado, su ámbito es más reducido con espacios igualitarios aunque hay cierta especialización respecto al trabajo laboral relacionado con el sexo. Este planteamiento nos parece interesante como modelo para entender la funcionalidad del espacio doméstico de los grupos Caillama tal vez estructurado bajo una unidad central que sería la aldea y un pequeño espacio protector manifestado por el recinto donde el grupo familiar se resguardó y protegió de las noches heladas de la precordillera de Arica.

\section{Excavaciones y Resultados de los Materiales}

La información de la excavación proviene de seis recintos habitacionales. El trabajo se realizó en el sector central y cima del asentamiento, pues allí los recintos se conservan en mejor estado, con una clara estratigrafía y elementos en superficie de actividades domésticas. Acompaña esta descripción el registro del equipo doméstico representado en la cerámica tanto en sus formas como diseños y el análisis químico.

Sector Central. Se ubica en el sector medio del cerro concentrando la mayor cantidad de recintos, se caracteriza por un pasillo central, el que a su vez divide el área habitacional en dos sectores. En los espacios de mayor pendiente observamos la presencia de peldaños construidos en piedras.

Recinto 123. Ubicado en el centro del promontorio; recinto de forma oval, presenta muros construidos en doble hilada de piedras (Figura 6). La superficie presenta restos de cenizas, asociados a fragmentos cerámicos que se distribuyen a lo largo del recinto; en el centro se encontró un mortero de superficie plana tipo batán, de $73 \mathrm{~cm}$ de diámetro. Hacia el sector este se ubica una cocina compuesta por dos hiladas de piedras. Una cocina con las mismas características constructivas se halla en el sector noreste. Ambas están asociadas a restos de fogones y basuras. En el centro del recinto se encontraron piedras de diversos tamaños 20 a $30 \mathrm{~cm}$ de diámetro, una boleadora y 12 fragmentos de palas líticas. La estratigrafía del recinto es de 5-7 cm de espesor, no presenta ocupaciones posteriores, está conformada por arcilla, restos de lana hilada, fragmentos de huesos de aves y de roedores, tres fragmentos de conchas marinas (choros), un tubérculo, posiblemente papa, junto a restos de raíces y gramíneas.

Equipo doméstico: En el recinto 123 se tomó como material de referencia la Cuadrícula A-2, por presentar mayor cantidad de fragmentos de cerámicas, donde se encontraron 140 fragmentos. Las formas más representativas corresponden a fragmentos de ollas (55\%), jarras (2\%) y escudillas (1\%), el $42 \%$ no se pudo identificar. Dentro 


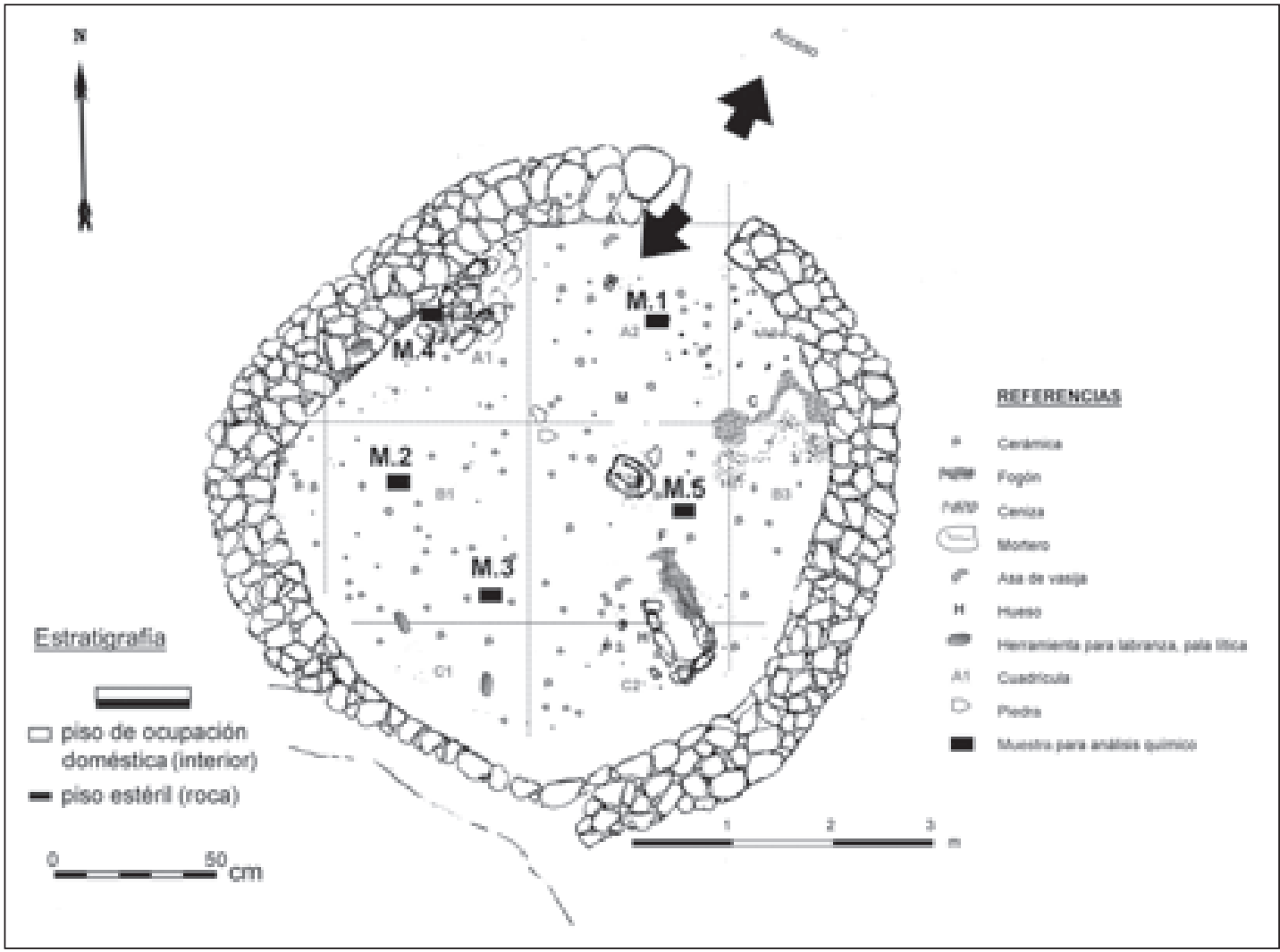

Figura 6. Planta arquitectónica y distribución interior recinto 123.

Architectonic plan and distribution of enclosure 123.

de las formas de ollas se identificaron doce bordes, siete bases de forma redondeada y cuatro asas de forma curva. En cuanto a la decoración se identificaron fragmentos con engobe rojo y decoración lineal y ondulada de color negro, conocido como estilo altiplánico (4\%) y el estilo Arica (3\%).

Análisis químico: Del interior del recinto se tomaron cinco muestras (Figura 6). El suelo de la muestra 1 se asocia a consumo de alimentos, ya que la concentración de fosfato es alta. El alto valor de pH indicaría quemazón de desechos, además hay presencia de ácidos grasos y restos de proteínas. Los suelos de las muestras 2 y 5 se asocian al calentamiento y consumo de alimentos, ya que la concentración de fosfato y el valor de $\mathrm{pH}$ son altos, probablemente estén relacionados a áreas de cocina, además hay residuos de ácidos grasos y restos de proteínas. La evidencia física del suelo de color gris oscuro, cenizas y restos vegetales indica que hubo combustión. Los suelos 3 y 4 no entregan información que permita diferenciar claramente ti- pos de actividades como combustión y consumo de alimentos. Sin embargo, por la información asociada, restos de cenizas, también podría corresponder a zonas de calentamiento (fogatas).

Recinto 124. Ubicado en el centro del promontorio, recinto de forma oval construido por un muro de doble y triple hiladas de piedras (Figura 7), la entrada es por el suroeste. En el recinto se hallaron restos de fragmentación cerámica, en el centro un mortero de $44 \mathrm{~cm}$ de diámetro con una pequeña cavidad central, junto a una mano para moler. En el sector este se encontraron restos de cenizas y carbones. En este sector se halló un recinto de cocina con muros de dos hiladas de piedras en cuyo interior se encontraron restos de cenizas y fogones de 30 y $40 \mathrm{~cm}$. Hacia el sector suroeste presenta una división interior de forma circular con muros de doble hilada de piedras, su entrada es por el sector oeste. En esta subdivisión aparecen restos de un "poyo" ${ }^{2}$, cocina y fragmentación de cerámica sin decoración. Tanto en el recinto como en su subdi- 


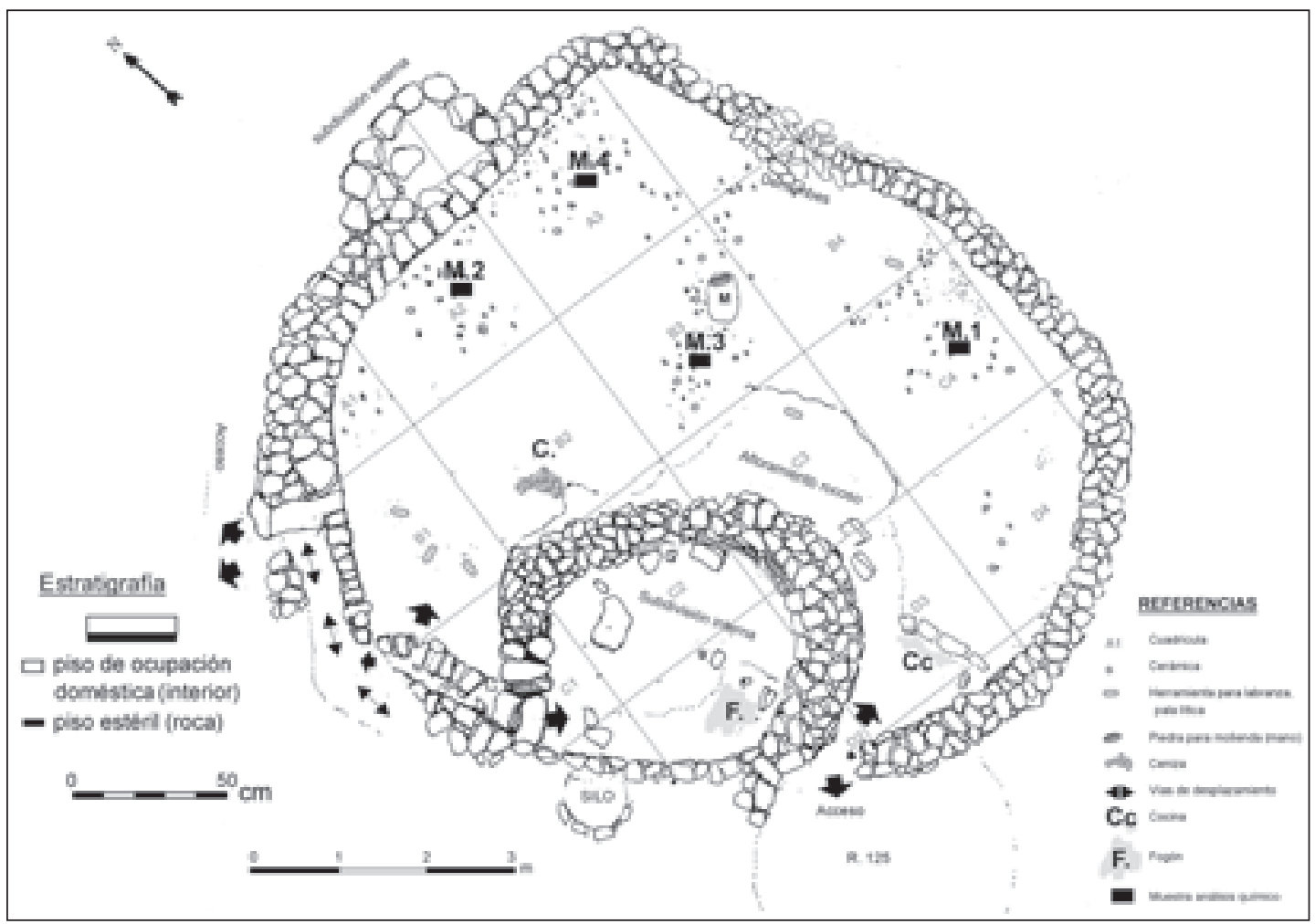

Figura 7. Planta arquitectónica y distribución interior recinto 124.

Architectonic plan and distribution of inner enclosure 124.

visión se encontraron fragmentos de palas líticas. Adosado a la pared exterior por el suroeste observamos un silo de forma circular y hacia el norte una estructura semicircular.

La estratigrafía del recinto está conformada por un estrato de $5 \mathrm{~cm}$ de espesor. En este estrato no observamos variaciones estratigráficas que nos lleven a postular una superposición de períodos; hay un patrón estándar en cuanto a los componentes de una ocupación tardía de carácter doméstica (cocinas, fogones, división interior de los recintos, etc.). En el estrato se halló material orgánico, cenizas, arcilla, fragmentos de cerámicas, restos de huesos de aves y camélidos, una mazorca de maíz, maderos sin trabajar e hilados de lana.

Equipo doméstico: Se tomó como material de referencia la Cuadrícula B-3, en la que se hallaron 135 fragmentos de cerámica. Las formas más representativas corresponden a ollas (67\%), jarras (9\%) y escudillas (6\%); dentro de las ollas se identificaron 17 bordes, ocho bases de forma redondeada y cinco asas en forma curva. En cuan- to a los estilos se reconocieron los que se asocian a la Cultura Arica (2\%), al altiplánico caracterizado por engobe rojo con decoración en negro (6\%) y Charcollo (1\%).

Análisis químico: En el interior se tomaron cuatro muestras. El suelo de la muestra 3 se asocia a preparación de alimentos, ya que la concentración de fosfato es baja y el valor de $\mathrm{pH}$ es alto, hay presencia de ácidos grasos y restos de proteínas; además, las características físicas del suelo muestran un suelo gris oscuro, con presencia de cenizas, lo cual implica que hubo combustión. Los otros suelos muestreados, 1, 2 y 4, si bien sirven para obtener una imagen global del sector, no entregan una información específica de las actividades domésticas, aunque por la información de ácidos grasos podría corresponder a preparación de alimentos.

Recinto 144. Ubicado en el sector medio del asentamiento, entre el barranco del promontorio y adosado al pasillo central, tiene forma oval y los muros de una y doble hileras de piedras (Figura 8). La entrada al recinto es por el sector oeste, pre- 


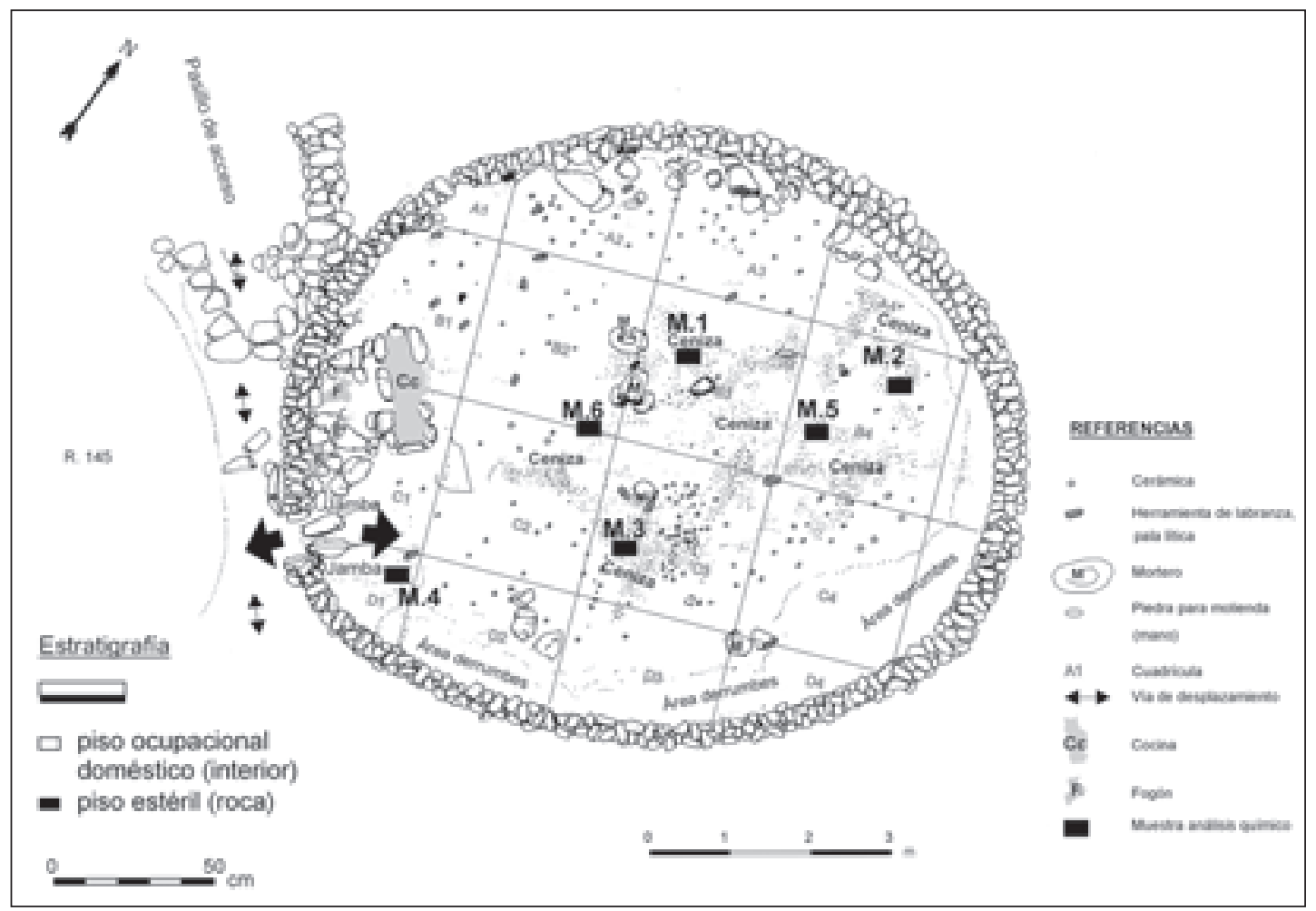

Figura 8. Planta arquitectónica y distribución interior recinto 144.

Architectonic plan and distribution of inner enclosure 144.

sentando jambas. En su interior se hallaron tres morteros, uno de superficie plana tipo batán y otro de forma cónica ambos ubicados en el centro del recinto. En el sector suroeste se ubica el tercer mortero, de base plana, presenta una leve hendidura y se asocia a una mano de moler. En el sector oeste adyacente a la entrada del recinto se halló un área de cocina delimitada por muros de una hilada de piedras. En el sector central se registraron restos de cenizas asociados a fragmentación de cerámica y palas líticas. La estratigrafía está constituida por un depósito de $5 \mathrm{~cm}$, sin que se observe una reocupación del recinto, está compuesta por arcilla, cenizas, fogones, material orgánico, etc. Entre los recursos de subsistencia se hallaron restos de huesos de roedores, camélidos y aves; granos de quinoa y restos de tubérculos, fragmentos de conchas (Choromythilus y Concholepas), además de caracoles (Oliva peruviana) y vértebras de pescado. Entre los objetos culturales se encontraron dos bolas de boleadoras muy pulidas, un machacador, un tortero de cerámica e hilados de fibra de camélido.
Equipo doméstico: Se tomó como material de referencia la Cuadrícula C-2 (Figura 8) por presentar el mayor número de restos de cerámica, en ella se hallaron 182 fragmentos. El mayor número de formas corresponde a ollas $(65 \%)$, de la parte central del cuerpo del alfar, en menor porcentaje encontramos jarros (7\%) y escudillas (2\%). En las formas de ollas se identificaron 12 bordes, nueve bases de forma redondeada y semiplana y cuatro asas en forma curva. En cuanto a los estilos, éstos están vinculados a la Cultura Arica (3\%), Negro sobre Rojo (4\%) y Charcollo (1\%).

Análisis químico: En el interior del recinto se obtuvieron seis muestras de suelos (Figura 8). Los suelos de este sector no entregaron información clara, ya que los resultados no presentan una diferencia muy marcada entre ellos, lo que dificulta llegar a una interpretación definitiva. Sin embargo la muestra 4 presenta un alto nivel de fósforo, lo cual asociado a restos de ácidos grasos y carbonato sugerirían que en este piso se consumie- 
ron alimentos. Las muestras 1, 2, 3, 5 y 6 presentan carbonatos y ácidos grasos, lo cual sugeriría un consumo bajo de alimentos.

Recinto 151. Corresponde a un recinto de forma oval ubicado en el sector alto del promontorio. El recinto presenta dos entradas con jambas laterales, orientadas hacia el noreste y suroeste, tienen un ancho de 97 y $82 \mathrm{~cm}$ aproximadamente (Figura 9). Los muros fueron construidos con doble y triple hiladas de piedras. El muro que se orienta hacia el sureste es de forma recta. En el interior del recinto en la parte noreste se hallaron restos de dos áreas de cocina con fogones y cenizas. En el centro se registraron restos de dos morteros, uno de forma cónica y otro plano, tipo batán de 40 y $20 \mathrm{~cm}$ de diámetro. El último mortero se halla asociado a una mano de moler. Las áreas de cocina están circunscritas por dos hileras de piedras. En su interior se hallaron restos de plantas quemadas y fragmentos de cerámica, entre los cuales destaca un fragmento estilo Gentilar (cocina 1). En la parte central del recinto se halló un poste de madera de $8,5 \mathrm{~cm}$ de diámetro, con la superficie del extremo superior quemada. En el sector central se detectaron en la base del piso de ocupación tres fogones con diámetros que oscilan entre 15 a $21 \mathrm{~cm}$, el estrato ocupacional presenta un espesor de $6 \mathrm{~cm}$. El estrato está compuesto por cenizas, restos orgánicos y piedras. Además, fueron halladas dos mazorcas de maíz, fragmentos de maderas, restos de semillas de gramíneas, bulbos y raíces. En cuanto al material faunístico se hallaron restos de huesos de camélidos y roedores, además de vértebras de pescados, conchas (Choromythilus y Concholepas) y caracoles (Oliva peruviana). Desde el punto de vista cultural aparecieron palas y azadones líticos, varios en proceso de elaboración. Este recinto externamente presenta hacia el suroeste un muro de piedras que lo comunica con el pasillo central.

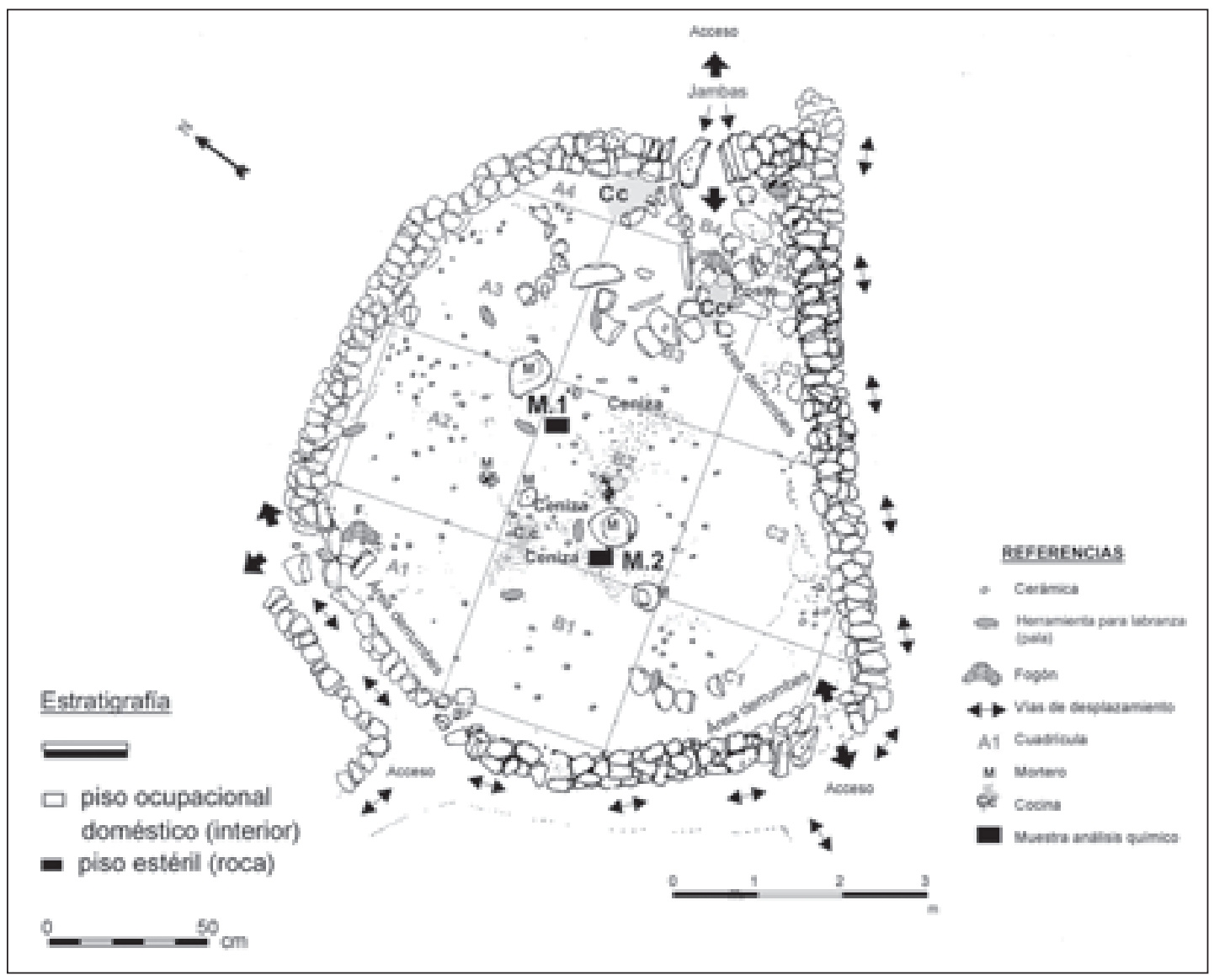

Figura 9. Planta arquitectónica y distribución interior recinto 151.

Architectonic plan and distribution of inner enclosure 151. 
Equipo doméstico: El material estudiado se tomó de la Cuadrícula B-2 por presentar mayores evidencias de restos de cerámicas, en ella se encontraron 136 fragmentos. El mayor número de formas corresponden a ollas (67\%), jarras (5\%) y escudillas (3\%). En las ollas se identificaron ocho bordes de formas redondeadas, seis bases de forma redondeada y cinco asas de forma curva. Se hallaron fragmentos pertenecientes a la Cultura Arica, como el estilo Gentilar (2\%), pastas rojas y naranja, asociadas a los estilos altiplánicos Negro sobre Rojo (3\%) y Charcollo (1\%).

Análisis químico: Se tomaron dos muestras del recinto. El suelo de la muestra 1 se asocia a la preparación de alimentos, ya que la concentración de fosfato es baja y el valor de $\mathrm{pH}$ es alto, además hay presencia de ácidos grasos, residuos de proteínas; las características físicas del suelo nos muestran un suelo gris oscuro, con presencia de cenizas. El suelo de la muestra 2 presenta menos fosfato y ácidos grasos, lo que hace pensar en un sector de calentamiento sin comidas.
Recinto 175. Corresponde a un recinto de forma oval construido en doble y triple hiladas de piedras (Figura 10). La entrada, a pesar que el material está derrumbado, está ubicada por el lado sur; presenta dos jambas de $112 \mathrm{~cm}$ lado sur y $44 \mathrm{~cm}$ lado norte. En su interior a diferencia de los otros recintos excavados presenta escaso material cultural. En su superficie en la parte central se hallaron cuatro morteros de forma plana y cónica. Fragmentación de cerámica en general sin decoración se distribuye por todo el perímetro interior del recinto, externamente presenta un pasillo escalerado construido con una o dos hiladas de piedras, construcción que sirve para reforzar, además, el muro noroeste del recinto. La estratigrafía de este recinto presenta un espesor de $5 \mathrm{~cm}$, compuesta por cenizas, restos orgánicos y pequeñas piedrecillas. Algunos objetos encontrados fueron un tortero de cerámica, dos boleadoras y seis palas líticas usadas como instrumentos de labranza.

Equipo doméstico: El material de referencia trabajado proviene de la Cuadrícula 2, en la que se

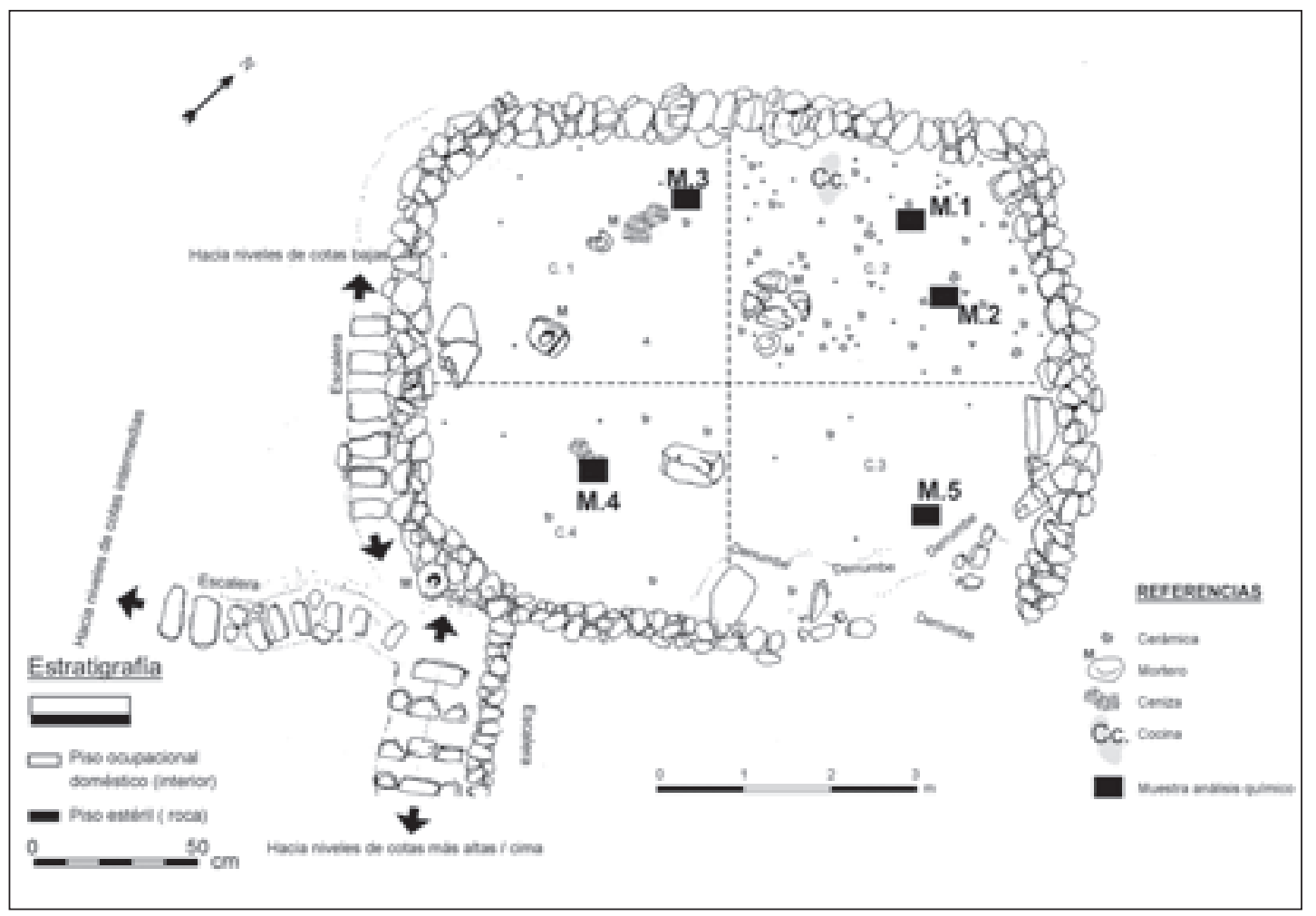

Figura 10. Planta arquitectónica y distribución interior recinto 175.

Architectonic plan and distribution of inner enclosure 175. 
encontraron 52 fragmentos de cerámica. El mayor número de formas corresponde a ollas (64\%), jarras $(6 \%)$ y escudillas (3\%). En los fragmentos de ollas se identificaron siete bordes, cuatro bases de forma redondeada y dos asas de forma curva. Los estilos reconocidos fueron engobes rojos con decoración lineal en negro (2\%) y el estilo Charcollo $(2 \%)$.

Análisis químico: Se tomaron cinco muestras del recinto ubicadas en la Figura 10; sin embargo, los resultados no presentan una diferencia muy marcada, aunque la presencia de restos de proteínas y ácidos grasos sugeriría que en estos espacios se consumieron alimentos.

Sector Cima. En ella hallamos una serie de recintos que fueron ocupados como recintos habitacionales, teniendo como indicador principal la presencia de basuras y morteros.
Recinto 197. Se ubica en la cima del abrupto montículo central de Caillama. El recinto presenta forma oval, los muros fueron construidos de doble y triple hiladas de piedras (Figura 11) Las entradas se ubican hacia el norte y sur y presentan jambas de $70 \mathrm{~cm}$ de altura. En el interior del recinto se observan grandes manchones de cenizas y fogones, así como en la totalidad del recinto se hallaron fragmentos de cerámica. En el centro se ubicaron tres morteros de forma plana con bordes canteados. Adosados a la pared sur se hallaron restos de áreas de cocina circunscritos por dos hiladas de piedras de $90 \mathrm{~cm}$ de largo y $40 \mathrm{~cm}$ de ancho en cuyo interior se encontraron restos de cenizas y carbones. En el área oeste del recinto se halló un sector de preparación de alimentos; constituido por cuatro fogones de 20,30,35 y $40 \mathrm{~cm}$ de diámetro. La estratigrafía alcanza los $5 \mathrm{~cm}$ de espesor, presenta restos de cenizas, arcilla y material orgánico; en ella fueron encontrados frag-

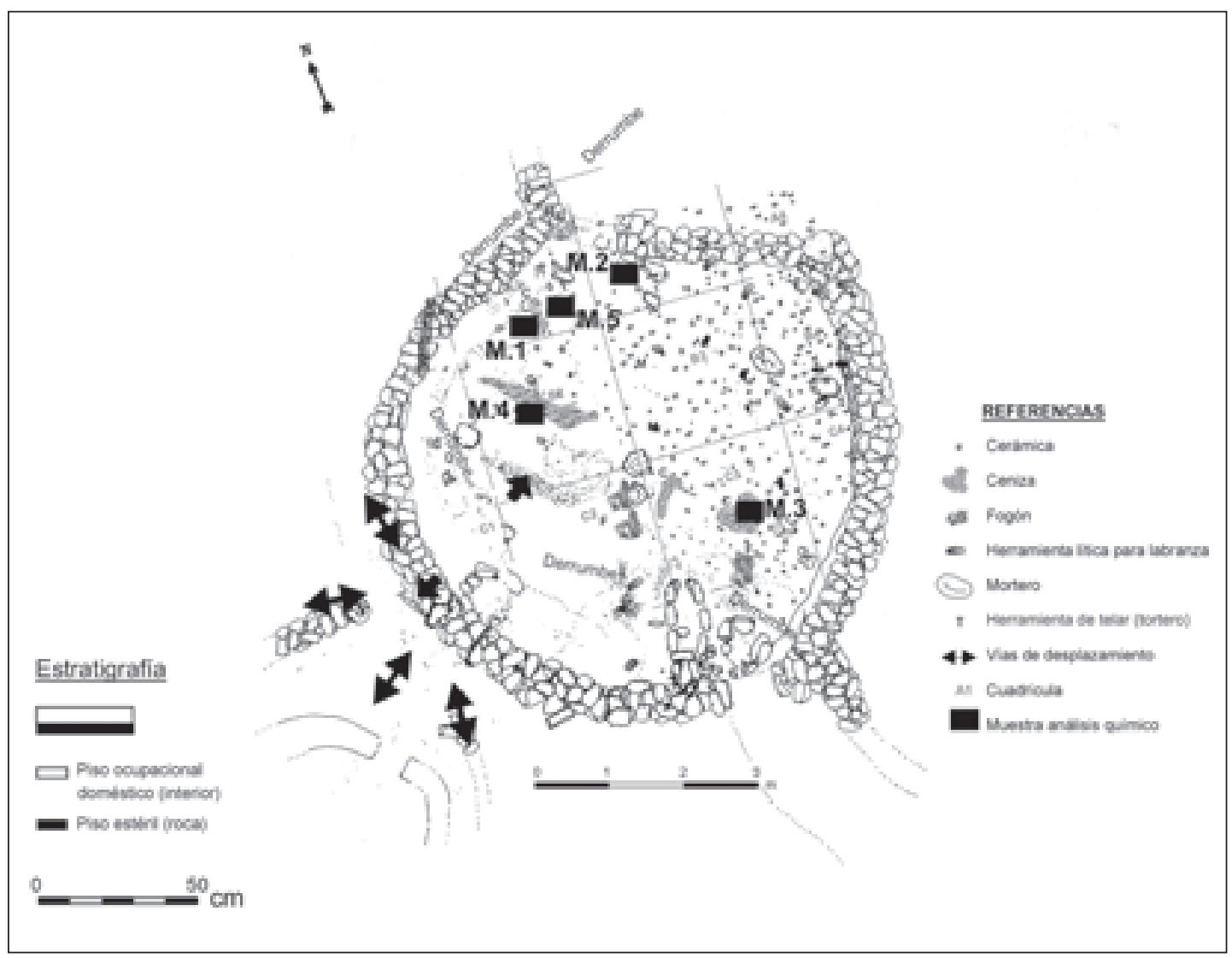

Figura 11. Planta arquitectónica y distribución interior recinto 197.

Architectonic plan and distribution of inner enclosure 197. 
mentos de palas líticas, una piedra usada como boleadora, un machacador, hilos de lana y dos torteros de cerámica. En cuanto a los recursos de subsistencia se encontraron huesos de camélidos y roedores, conchas (Choromythilus, Concholepas) y caracoles (Oliva peruviana), además un tubérculo no identificado, maderos y gramíneas.

Equipo doméstico: El material de referencia proviene de la Cuadrícula C-3 por presentar mayor cantidad de restos de cerámica en relación con las otras cuadrículas. Se hallaron 167 fragmentos de cerámica. El mayor número de formas corresponde a ollas $(68 \%)$, jarras $(7 \%)$ y escudillas $(3 \%)$. En los fragmentos de ollas se identificaron 15 bordes, ocho bases de forma redondeada y cuatro asas de forma curva. En cuanto a los estilos se hallaron fragmentos de pastas rojas con engobes con figuras negras onduladas $(2 \%)$. Se encontró un fragmento con rostro antropomorfo, presenta en sus extremos dos orificios, lo que pudo corresponder a una figura decorativa. Finalmente fueron registrados fragmentos pertenecientes a la Cultura Arica (2\%).

Análisis químico: De su interior se tomaron cinco muestras ubicadas en la Figura 11. El suelo de la muestra 1 se asocia al calentamiento y consumo de alimentos, ya que la concentración de fosfato es alta y el valor de $\mathrm{pH}$ es bajo, además se hallaron residuos de ácidos grasos y proteínas. Las características físicas del suelo de color gris, sumado a la presencia de cenizas y algunos residuos carbonizados indicarían un espacio de preparación de alimentos. El suelo de la muestra 2 se asocia a la preparación de alimentos, ya que la concentración de fosfato es baja y el valor de $\mathrm{pH}$ es elevado. Además hay presencia de residuos de ácidos grasos y proteínas. Las características físicas del suelo: color gris, presencia de cenizas y algunos residuos carbonizados, indican además preparación de alimentos. El resto de suelos muestreados 3, 4 y 5 presentan residuos de fosfato medianamente altos, además de ácidos grasos y proteínas, lo que nos induce a pensar que se calentó alimento.

\section{Áreas de actividad y espacio doméstico en el interior de las viviendas de Caillama}

Del resultado de las excavaciones y procesamiento de los materiales hemos podido definir las siguientes áreas de actividad.
Áreas de molienda. Se caracterizan por la presencia de morteros, ubicados por lo general en el centro de los recintos, de formas cónicas y planas, construidos en grandes bloques naturales de granito y arenisca, tienen formas circulares u ovaladas, con la cara ligeramente convexa. La cara plana del batán y el costado activo de las manos presentan un desgaste debido a la fricción de productos vegetales. La presencia de mazorca de maíz en una de las estructuras, así como el hallazgo de granos de quinoa, bulbos y raíces de tubérculos sin identificar sugieren que estas plantas fueron parte de los alimentos y pudieron haber sido molidas en los morteros anteriormente descritos. Esta área de molienda está relacionada directamente con el área de cocina y preparación de alimentos.

Áreas de preparación y consumo de alimentos. Todos los recintos excavados se relacionan con restos de basuras como consecuencia de la preparación y consumo de alimentos (Figuras 12 y 13). En ellos encontramos en general una alta concentración de fosfato, junto a un alto valor de $\mathrm{pH}$, indicadores que en los pisos de ocupación de los recintos excavados se llevaron a cabo actividades de alimentación preparada en las cocinas; la presencia de ácidos grasos y restos de proteínas y carbonatos apoyaría la hipótesis de preparación y consumo de alimentos. A partir de estas evidencias reconocidas en el análisis químico la pregunta es ¿qué alimentos habrían consumido las poblaciones de Caillama? A pesar que las evidencias son escasas, parte de la alimentación estuvo constituida por maíz (Zea mays) y quinoa (Chenopodium quinoa), también el consumo de tubérculos, posiblemente papa reconocida en el recinto 123. También consumieron carne de camélidos y posiblemente aves, estas últimas sin identificar la especie, también fueron consumidores de roedores (posiblemente cuyes y vizcachas). Otros productos complementarios fueron pescados y moluscos, estos últimos locos (Concholepas concholepas) y choros (Choromythilus chorus) traídos de la costa del Pacífico, así como los caracoles de mar, utilizados posiblemente para la confección de ornamentos.

Áreas de cocinas y fogones. Se caracterizan por pequeños pircados de piedras angulosas que conservan un fogón en el centro. Otro tipo de fogón está dado por una cavidad revestida con pequeñas 


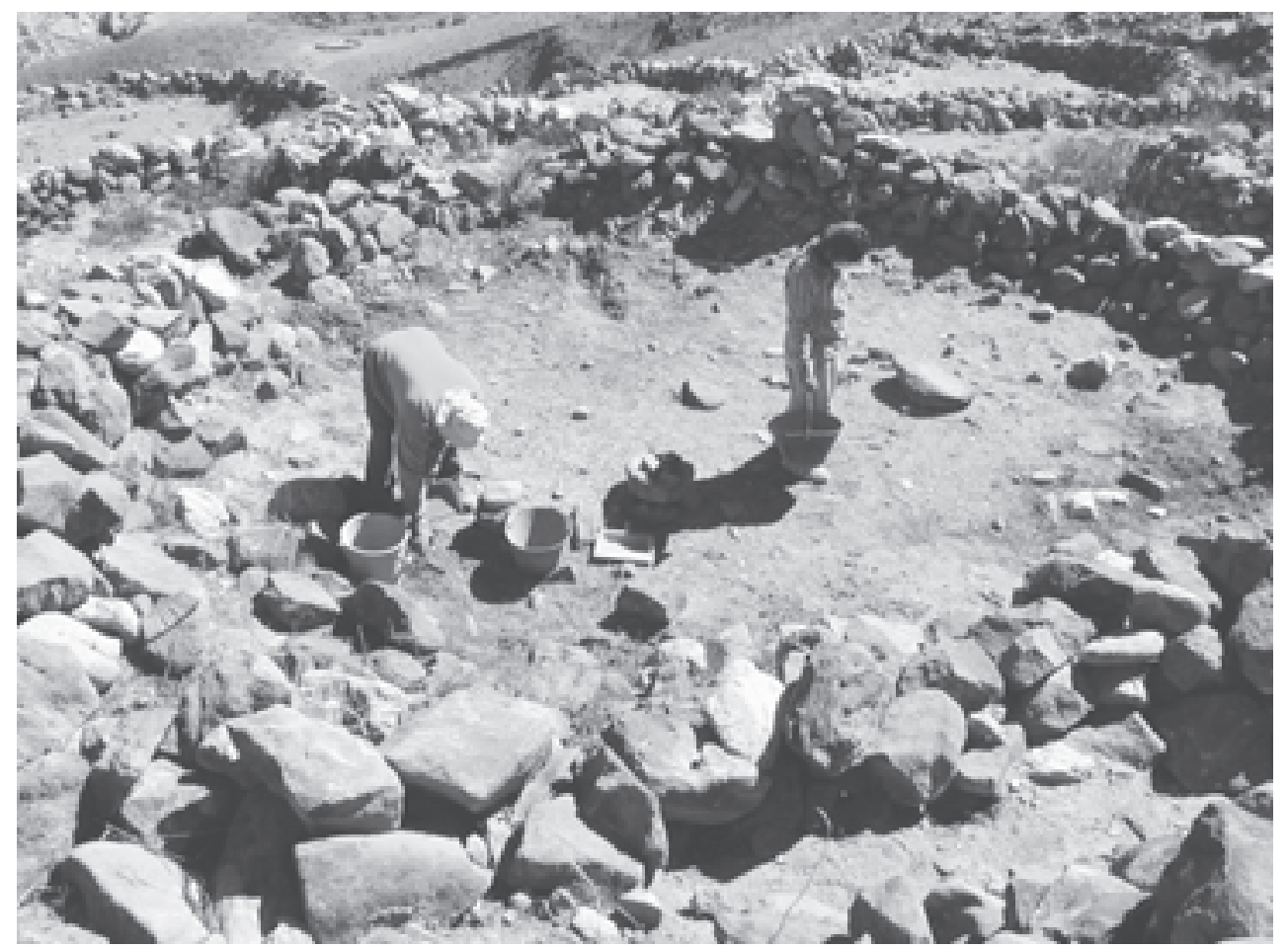

Figura 12. Excavación del piso ocupacional interno del recinto 175. Excavation of the occupational floor of enclosure 175.

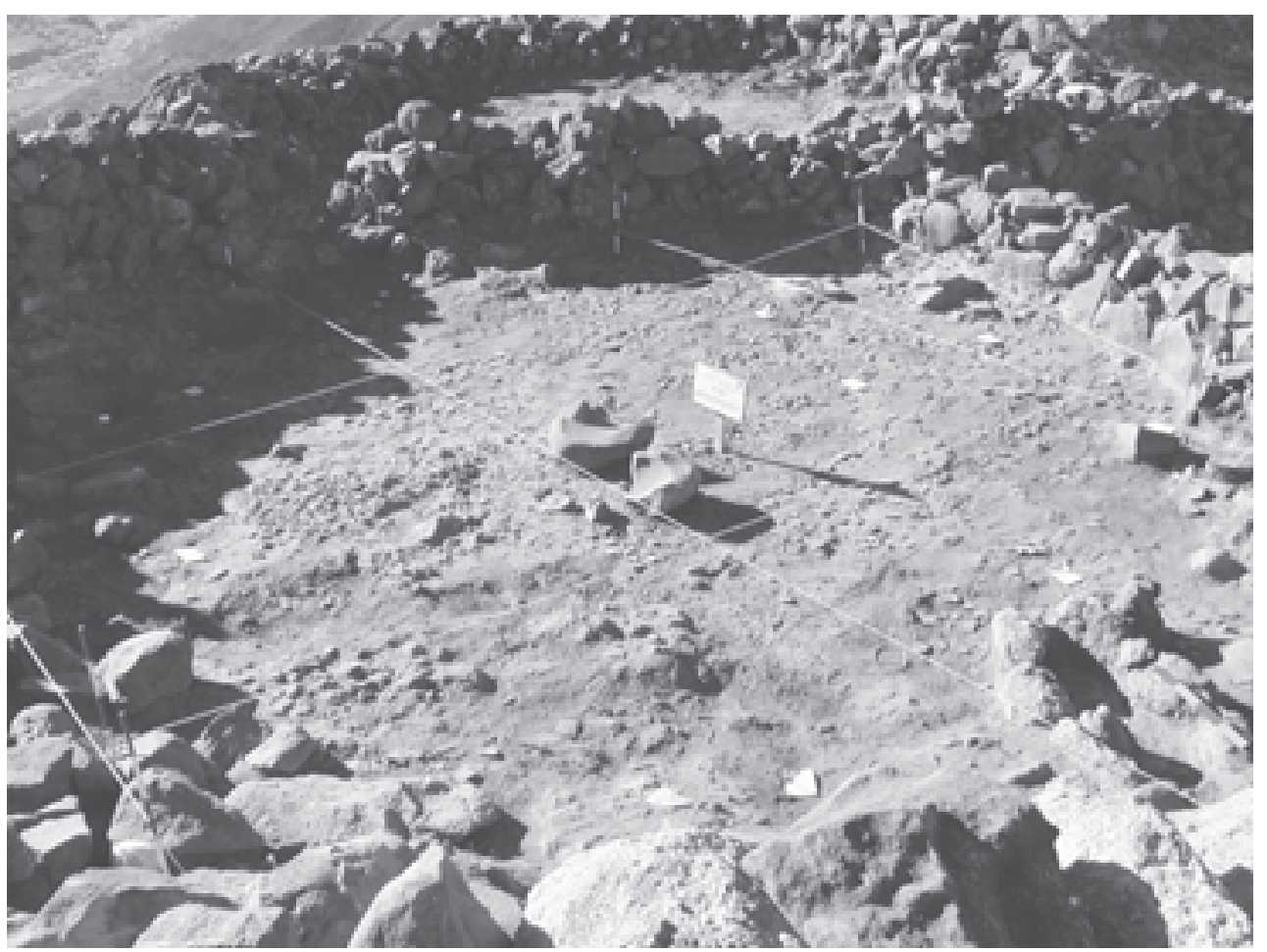

Figura 13. Despeje total del piso ocupacional interno, recinto 197.

Overall internal occupational floor, enclosure 197. 
piedras de río. Los fogones se caracterizan por manchas de formas irregulares, en algunos casos constituidas por una costra de color negro, salitrosa. Las áreas de cocina se ubican en sectores laterales adosadas al muro interior de los recintos, esta ubicación, tal vez, con el propósito de evitar que se ahumara el recinto.

La información proporcionada por los análisis químicos de suelos de los distintos recintos muestreados (Tabla 1) indica la posibilidad de cuatro áreas de actividad generada al interior de los recintos: (a) áreas de preparación de alimentos (cocinas), (b) áreas de consumo de alimentos, (c) áreas de calentamiento y probablemente (d) áreas de almacenamiento de alimentos, su mayor uso se comprueba en la preparación y consumo de alimentos que habrían tenido estos recintos preferentemente. Estos resultados son similares a lo planteado por Cook y Heizer (1965), en el sentido que se relacionan a desechos, como consecuencia de actividades humanas generadas en el interior de los recintos habitacionales.

Tabla 1. Valores de los componentes químicos en los pisos de ocupación de Caillama. Chemical components found in the soils of occupational floors of Caillama.

\begin{tabular}{|c|c|c|c|c|c|c|}
\hline Recinto & $\begin{array}{c}\text { Muestra } \\
\text { № }\end{array}$ & Restos proteínas & Carbonato & $\mathrm{pH}$ & Ácidos grasos & Fosfato (ppm) \\
\hline \multirow[t]{5}{*}{123} & 1 & 1 & 5 & 7,91 & 1 & 110,27 \\
\hline & 2 & 1 & 1 & 7,33 & 1 & 111,03 \\
\hline & 3 & 0 & 1 & 7,58 & 3 & 87,24 \\
\hline & 4 & 0 & 2 & 7,74 & 2 & 91,58 \\
\hline & 5 & 1 & 3 & 7,47 & 1 & 107,98 \\
\hline \multirow[t]{4}{*}{124} & 1 & 0 & 4 & 7,66 & 2 & 83,32 \\
\hline & 2 & 0 & 4 & 7,68 & 2 & 105,05 \\
\hline & 3 & 1 & 4 & 8,02 & 1 & 76,48 \\
\hline & 4 & 1 & 4 & 7,26 & 3 & 104,73 \\
\hline \multirow[t]{6}{*}{144} & 1 & 0 & 4 & 7,41 & 1 & 96,47 \\
\hline & 2 & 1 & 3 & 7,47 & 3 & 96,90 \\
\hline & 3 & 1 & 3 & 7,44 & 3 & 85,50 \\
\hline & 4 & 1 & 4 & 7,82 & 2 & 108,42 \\
\hline & 5 & 0 & 4 & 7,73 & 2 & 71,70 \\
\hline & 6 & 0 & 1 & 7,58 & 2 & 88,21 \\
\hline \multirow[t]{2}{*}{151} & 1 & & 2 & 7,10 & 3 & 82,24 \\
\hline & 2 & & 3 & 7,80 & 2 & 22,71 \\
\hline \multirow[t]{5}{*}{175} & 1 & 1 & 3 & 7,84 & 2 & 90,39 \\
\hline & 2 & 0 & 1 & 7,13 & 1 & 69,85 \\
\hline & 3 & 1 & 4 & 7,75 & 3 & 110,59 \\
\hline & 4 & 0 & 4 & 7,16 & 3 & 79,41 \\
\hline & 5 & 1 & 1 & 7,32 & 1 & 83,43 \\
\hline \multirow[t]{5}{*}{197} & 1 & 0 & 1 & 6,82 & 3 & 138,29 \\
\hline & 2 & 1 & 3 & 7,97 & 3 & 72,57 \\
\hline & 3 & 1 & 2 & 7,79 & 1 & 100,27 \\
\hline & 4 & 1 & 2 & 7,78 & 2 & 107,33 \\
\hline & 5 & 1 & 1 & 7,43 & 2 & 112,00 \\
\hline
\end{tabular}


Áreas de confección de artefactos. En el espacio central de los recintos fueron hallados hilados de lana y tres torteros confeccionados en cerámica, instrumentos que fueron utilizados para hilar; por otro lado y distribuidas a lo largo de los recintos se encontraron 32 palas líticas, varias de ellas en proceso de elaboración. Por su forma según la tipología establecida por Lavallèe y Julien (1983) hemos definido dos tipos. El primero son "picos" confeccionados en andesita, se caracterizan por su forma semicilíndrica, de 7 a $12 \mathrm{~cm}$ de largo y $15 \mathrm{~mm}$ de espesor, presentan bordes cortantes, algunos desgastados, lo que sugiere que fueron usados para trabajar la tierra. El segundo son "rompeterrones", confeccionados en placas de rocas talladas en forma discoidal. El hallazgo de ambos objetos -torteros y palas- sugiere que los pobladores al interior de las viviendas realizaron actividades paralelas como fue la confección o retoques de objetos mientras cocinaban y comían.

En síntesis, sobre la base de los antecedentes anteriormente descritos y la información de la Tabla 2 podemos señalar que las actividades domésticas al interior de los recintos del sitio de Caillama se organizaron en sectores de preparación y consumo de alimentos, también se llevaron a cabo actividades de molienda, hilado y se retocaron y pulieron instrumentos de labranza (Figura 14). Como una forma de abrigarse probablemente durmieron cerca del área de preparación de alimentos. La presencia de un poste central como sostén principal de la techumbre del recinto permitió la ventilación y entrada de luz natural. Por el tipo de cerámica encontrada, su alta tendencia de formas globulares, pensamos que los alimentos fueron cocidos en ollas, guardándose en jarras líquido y alimentos y en escudillas granos y comidas. $\mathrm{La}$ presencia de cerámicas decoradas en los recintos

Tabla 2. Distribución en el espacio interior de los recintos. Distribution of the interior spaces of the enclosures.

\begin{tabular}{|c|c|c|c|c|c|c|}
\hline Rasgos & Recinto 123 & Recinto 124 & Recinto 144 & Recinto 151 & Recinto 175 & Recinto 197 \\
\hline Cerámica & espacio total & espacio total & espacio total & espacio total & espacio total & espacio total \\
\hline Morteros & centro & centro & centro & centro & centro & centro \\
\hline $\begin{array}{l}\text { División } \\
\text { interior }\end{array}$ & & $\begin{array}{l}\text { adjunto al } \\
\text { muro }\end{array}$ & & & & \\
\hline Postes & & & & centro & & \\
\hline Cocinas & $\begin{array}{l}\text { adosado al } \\
\text { muro }\end{array}$ & $\begin{array}{l}\text { adosado al } \\
\text { muro }\end{array}$ & $\begin{array}{l}\text { adosado al } \\
\text { muro }\end{array}$ & $\begin{array}{l}\text { adosado al } \\
\text { muro }\end{array}$ & $\begin{array}{l}\text { adosado al } \\
\text { muro }\end{array}$ & $\begin{array}{l}\text { adosado al } \\
\text { muro }\end{array}$ \\
\hline $\begin{array}{l}\text { Fogones y } \\
\text { cenizas }\end{array}$ & $\begin{array}{l}\text { centro, } \\
\text { adosados al } \\
\text { muro }\end{array}$ & $\begin{array}{l}\text { centro, } \\
\text { adosados al } \\
\text { muro }\end{array}$ & $\begin{array}{l}\text { centro, } \\
\text { adosados al } \\
\text { muro }\end{array}$ & $\begin{array}{l}\text { centro, } \\
\text { adosados al } \\
\text { muro }\end{array}$ & $\begin{array}{l}\text { centro, } \\
\text { adosados al } \\
\text { muro }\end{array}$ & $\begin{array}{l}\text { centro, } \\
\text { adosados al } \\
\text { muro }\end{array}$ \\
\hline Palas & $\begin{array}{l}\text { recinto } \\
\text { completo }\end{array}$ & centro & $\begin{array}{l}\text { recinto } \\
\text { completo }\end{array}$ & $\begin{array}{l}\text { recinto } \\
\text { completo }\end{array}$ & centro & $\begin{array}{l}\text { recinto } \\
\text { completo }\end{array}$ \\
\hline Basuras & espacio total & centro & espacio total & espacio total & espacio total & espacio total \\
\hline Silos (pozos) & & $\begin{array}{l}\text { fuera del } \\
\text { recinto }\end{array}$ & & & & \\
\hline Machacador & & & & & & $\begin{array}{l}\text { asociado a } \\
\text { cocina }\end{array}$ \\
\hline $\begin{array}{l}\text { Objetos } \\
\text { diversos } \\
\text { (torteros, } \\
\text { hilados y } \\
\text { boleadoras) }\end{array}$ & $\begin{array}{l}\text { asociado a } \\
\text { fogón, central }\end{array}$ & $\begin{array}{l}\text { asociado a } \\
\text { fogón, central }\end{array}$ & $\begin{array}{l}\text { asociado a } \\
\text { fogón, central }\end{array}$ & $\begin{array}{l}\text { asociado a } \\
\text { fogón, central }\end{array}$ & $\begin{array}{l}\text { asociado a } \\
\text { fogón, central }\end{array}$ & $\begin{array}{l}\text { asociado a } \\
\text { fogón, central }\end{array}$ \\
\hline
\end{tabular}




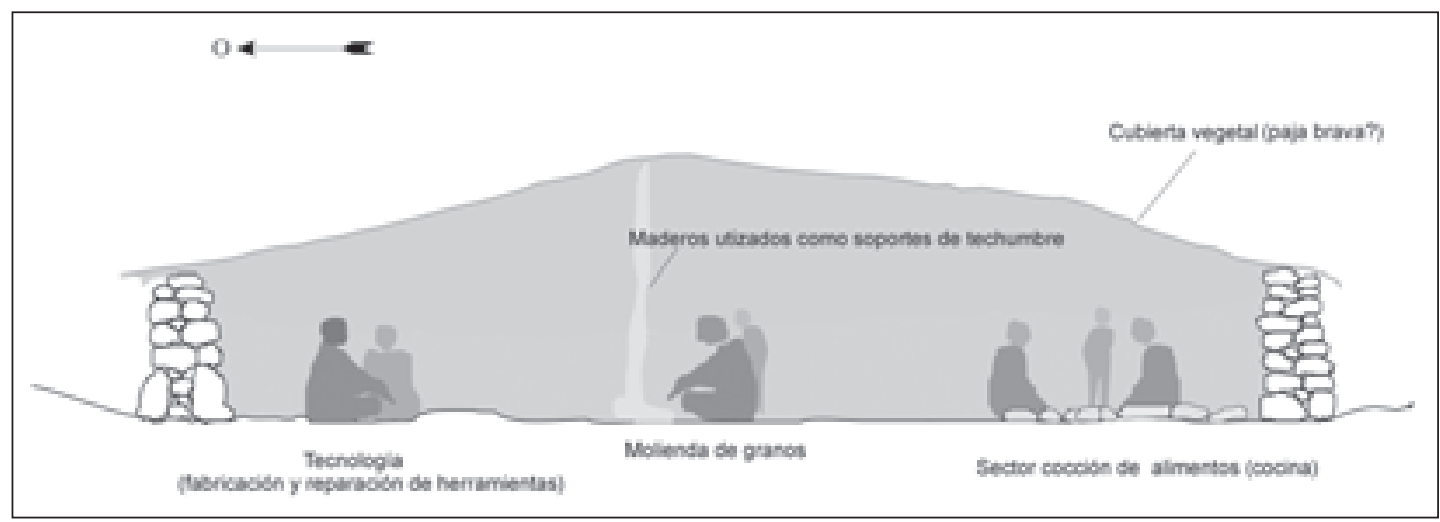

Figura 14. Reconstrucción hipotética de vivienda, recinto 151 (escala 1:50).

Hypothetical reconstruction of a house, enclosure 151 (1:50 scale).

habitacionales, aunque de baja proporción, explica el hecho que fueron recipientes usados también en el ámbito doméstico. Estos diseños se relacionan a estilos de origen altiplánico y costero, en este último incluimos el estilo posiblemente local denominado Charcollo (Figuras 15-18).

La mayor parte de las actividades reconocidas arqueológicamente al parecer se relacionan a una vida nocturna, ya que durante el día posiblemente en caso de la gente adulta estuvieron en sus terrazas de cultivos retornando a sus habitaciones durante el atardecer, de allí la presencia de las diversas quemazones y fogones que les permitieron abrigarse y llevar a cabo las actividades domésticas antes descritas. La concepción de percibir la aldea como el mayor espacio de habitabilidad nos sugiere que otros miembros del grupo familiar (niños pequeños, mujeres embarazadas y ancianos) durante el día pudieron haber habitado en espacios de mayor socialización como las plazas o estructuras de mayor tamaño de carácter colectivo.

\section{Comentarios Finales}

El estudio al interior de las viviendas en Caillama reconoce un espacio donde se dieron una serie de actividades relacionadas fundamentalmente con la preparación y consumo de alimentos, además de un espacio para abrigarse. Estas actividades por lo general se habrían organizado a par- tir del espacio central donde el fogón habría constituido el centro donde se reunieron los individuos y organizaron las actividades de cocina, alimentación, elaboración de instrumentos y dormir. De acuerdo con la función que se desarrolló en el interior de estas estructuras al igual como lo plantean Willey y Phillips (1958) y Chang (1976:27) constituyeron el eje central del patrón de asentamiento, la unidad básica donde se desarrolló la vida familiar de la comunidad de Caillama. Por otro lado, la edificación de los recintos requirió de una planificación y esfuerzo humano organizado, en el sentido que los muros de viviendas fueron construidos con doble y triple hiladas de piedras, levantadas sobre grandes bloques verticales bien acuñados, con apéndices internos que cumplían función de entrada, construcción de escalinatas para el tránsito más accesible y una subdivisión al interior de los recintos.

Agradecimientos: Este artículo es resultado del proyecto Fondecyt 1040296. El análisis químico fue realizado por Javier Cruz, Laboratorista Químico, encargado del laboratorio de Química de la Facultad de Agronomía, Universidad de Tarapacá. Se agradece también al Sr. José Rocha por el material gráfico y fotográfico procesado en el presente trabajo. Finalmente se agradecen los comentarios de los evaluadores que contribuyeron a mejorar este artículo. 


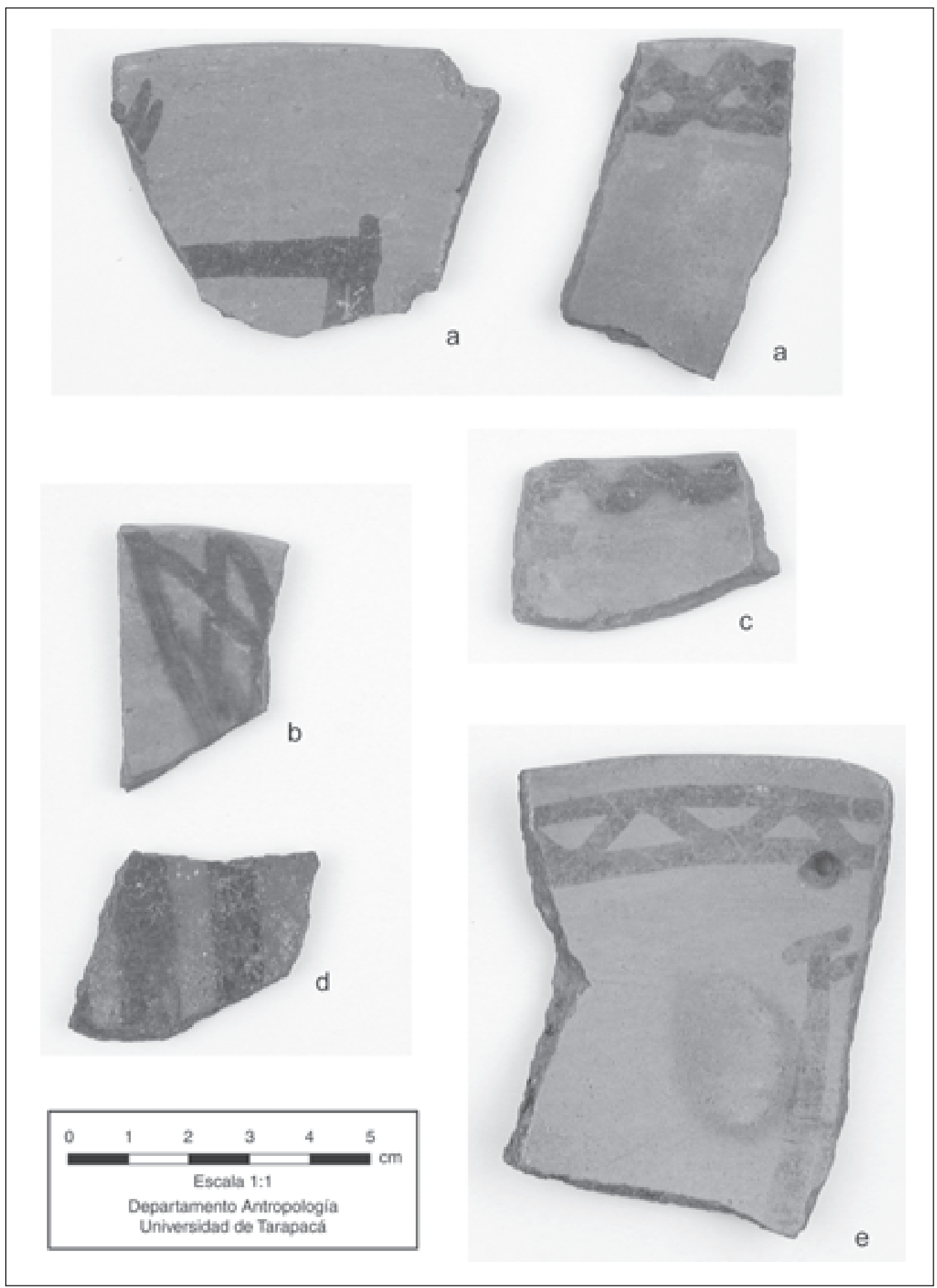

Figura 15. Cerámica Tradición Negro sobre pastas y engobes Rojo: (a) recinto 123, (b y c) recinto 197, (d) recinto 175 y (e) recinto 124 .

Black Ceramic Tradition on red pastes and slips (engobe): (a) enclosure 123, (b and c) enclosure 197, (d) enclosure 175 and (e) enclosure 124 . 


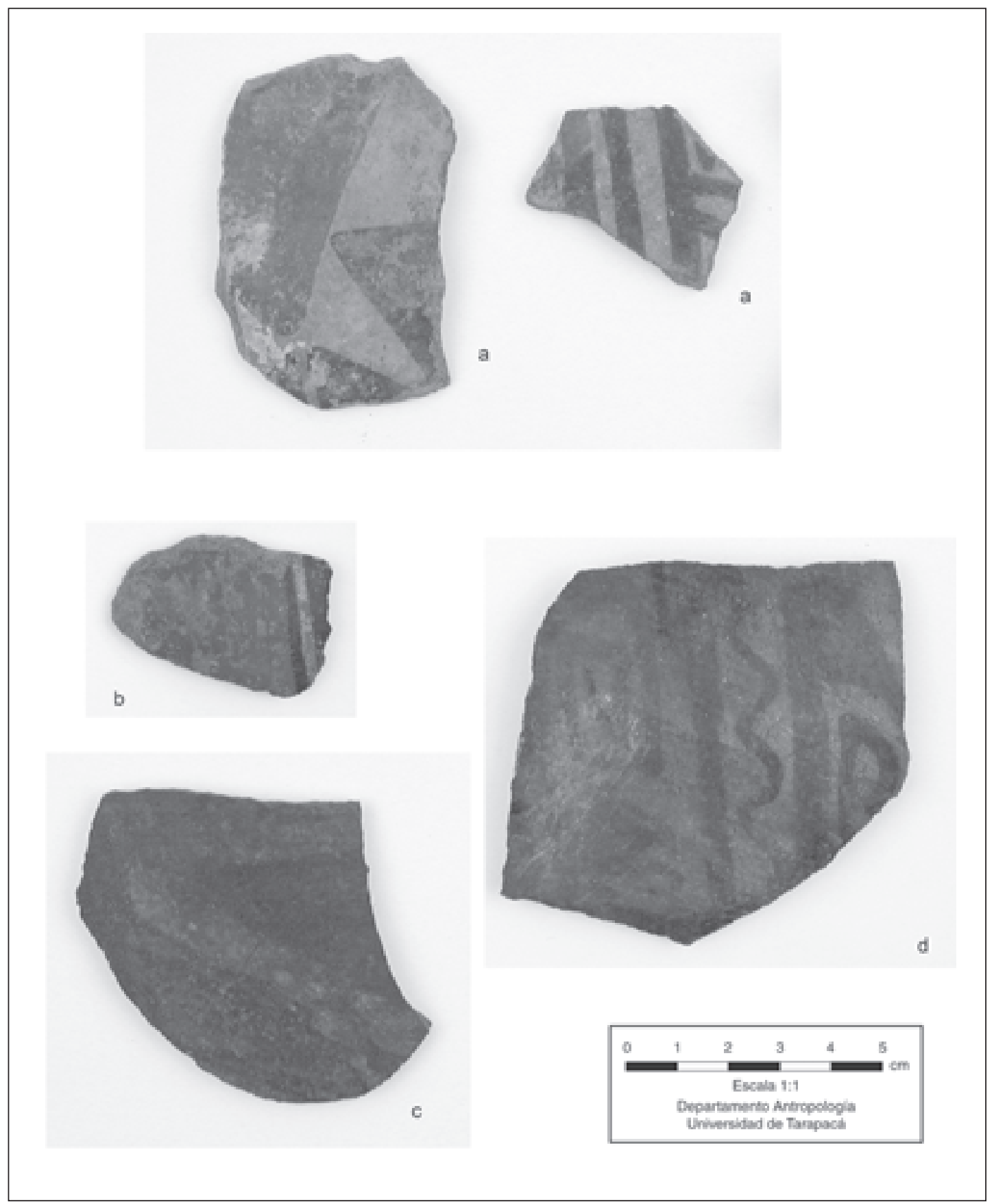

Figura 16. Cerámica Tradición Cultura Arica. Estilo Pocoma-Gentilar: (a) y (c) recinto 124, (b) recinto 123 y (d) recinto 144. Arica Culture Ceramic Tradition. Pocoma-Gentilar Style: (a) and (c) enclosure 124, (b) enclosure 123 and (d) enclosure 144. 


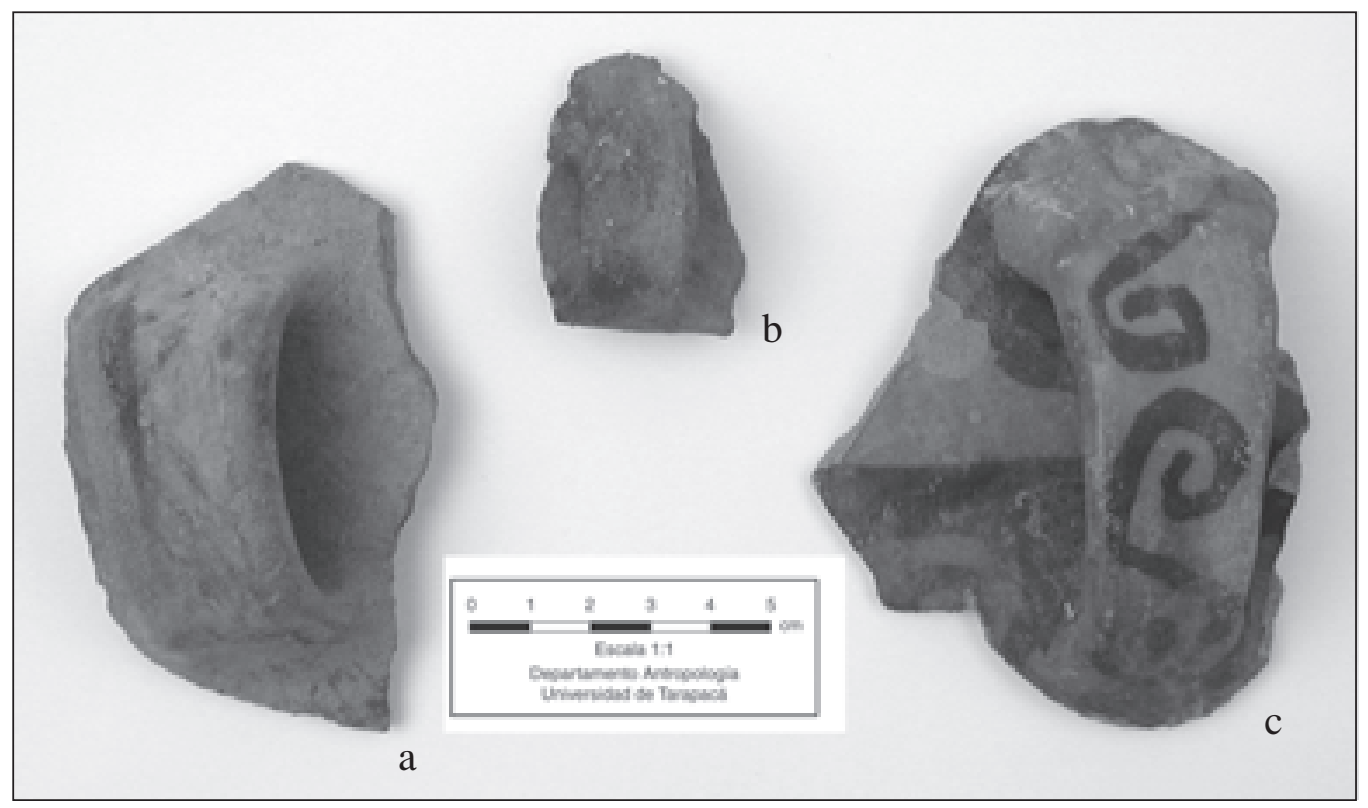

Figura 17. Asas: (a) recinto 144, (b) recinto 151 y (c) recinto 197.

Handles: (a) enclosure 144, (b) enclosure 151 and (c) enclosure 197.

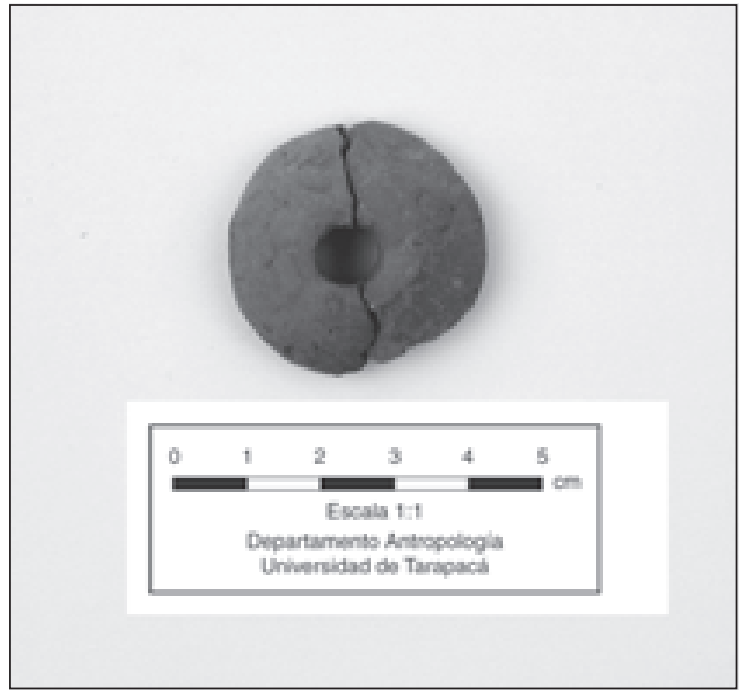

Figura 18. Tortero de greda, recinto 197, Cuadrícula B-3. Clay whorl, enclosure 197, grid B-3. 


\section{Referencias Citadas}

Albarracín, J. y J.E. Mathews

1990 Asentamientos Prehispánicos del Valle de Tiwanaku. Vol. 1. Cima, La Paz.

Aldenderfer, $\mathrm{M}$.

1993 Domestic space, mobility, and ecological complementarity: The view from Asana. En Domestic Architecture, Ethnicity, and Complementarity in the South-Central Andes, editado por M. Aldenderfer. University of Iowa Pres, Iowa City.

Barba, L.

1991 El análisis químico de pisos de unidades habitacionales para determinar sus áreas de actividad. Antropología y Técnica 4:195-207.

Barba, L. y L. Manzanilla

1987 Superficie/excavación. Un ensayo de predicción de rasgos arqueológicos en Oztoyohualco. Antropológicas I:19-45.

Barba, L. y J. Córdova

1999 Estudios energéticos de la producción de cal en tiempos Teotihuacanos y sus implicaciones. Latin American Antiquity 10:168-179.

Barba, L. y A. Ortiz

1992 Análisis químico de pisos de ocupación: un caso etnográfico en Tlaxcala, México. Latin American Antiquity 3:63-82

Bermann, M. y G. Graffman

1989 Arquitectura residencial en las terrazas de Lukurmata. En La Tecnología y Organización de la Producción Agrícola en el Estado de Tiwanaku, editado por A.L. Kolata, pp. 153-172. Editorial Sui Generis, La Paz.

Blanton, R.E.

1998 Beyond centralization: Steps toward a theory of egalitarian behavior in archaic states. En Archaic States, editado por G. Feinman y J. Marcus, pp. 135-172. School of American Research Press, Santa Fe.

Caiuby, S., M. Ladeira, A. da Silva, L. Vidal, C. Sa, D. Gallois y L. Hussak

1983 Habitaciones Indígenas. Nobel Editora da Universidade de São Paulo, São Paulo.

Chang, K.C.

1976 Nuevas Perspectivas en Arqueología. Alianza Editoral, Madrid.

Conrad, G.

1993 Domestic architecture of the Estuquiña Phase: Estuquiña and San Antonio. En Domestic Architecture, Ethnicity, and Complementarity in the South-Central Andes, editado por M. Aldenderfer, pp. 55-65. University of Iowa Press, Iowa City.

Cook, S. y R. Heizer

1965 Studies on the Chemical Analysis of Archaeological Sities. University of California Press, Berkeley.

Flannery, K.

1976 The Early Mesoamerica Village. Academic Press, New York.

Florín, C.A.

2001 Ser Social y Espacio Social en Arqueología. Tesis para optar al título de Maestro en Arqueología. Escuela Nacional de Antropología e Historia, México.
Goldstein, P.

1989 OMO, A Tiwanaku Provincial Center in Moquegua, Perú. Dissertation Ph.D. Department of Anthropology. The University of Chicago, Chicago.

Isbell, W.

1996 Mummies and Mortuary Monuments. A Postprocesual Prehistory of Central Andean Social Organization. University of Texas Press, Austin.

Janusek, J.

2001 Diversidad residencial y el surgimiento de la complejidad en Tiwanaku. Boletín de Arqueología PUCP 5:251294.

Kolata, A.

1989 Arqueología de Lukurmata. En La Tecnología y Organización de la Producción Agrícola en el Estado de Tiwanaku, editado por A.L. Kolata, pp. 13-40. Editorial Sui Generis, La Paz.

Kent, S.

1990 Activity areas and architecture: An interdisciplinary view of the relationship between use of space and domestic built environments. En Domestic Architecture and the Use of Space: An Interdisciplinary Cross-Cultural Study, editado por S. Kent, pp. 1-8. Cambridge University Press, Cambridge.

Lavallèe, D y M. Julien

1983 ASTO: Curacazgo Prehispánico de los Andes Centrales. Instituto de Estudios Peruanos, Lima.

Manzanilla, L.

1986 Unidades habitacionales Mesoamericanas y sus áreas de actividad. En Unidades Habitacionales Mesoamericanas y sus Áreas de Actividad. IIA/UNAM, México D.F

Middleton, W. y D. Price

1996 Identification of activity areas by multi-element characterization of sediments from modern and archaeological house floors using inductively coupled plasma-atomic emission spectroscopy. Journal of Archaeological Science 23:1-15.

Muñoz, I.

2005 Espacio social y áreas de actividad en asentamientos agrícolas prehispánicos tardíos en la sierra de Arica. $\mathrm{Bu}$ lletin de I'Institut Français d'Études Andines 34:321-355.

Muñoz, I. y J. Chacama

2006 Complejidad Social en las Alturas de Arica: Territorio, Etnicidad y Vinculación con el Estado Inca. Ediciones Universidad de Tarapacá, Arica.

Muñoz, I., J. Cruz y J. Chacama

2007 Identificación de las áreas de ocupación doméstica a través del análisis químico en el Pukara de Caillama período Intermedio Tardío. Actas del XVII Congreso Nacional de Arqueología Chilena (en prensa).

Nielsen, A.

2001 Evolución del espacio doméstico en el norte de Lipez (Potosí, Bolivia) ca. 900-1700 d.C. Estudios Atacameños 21:41-62.

Niemeyer H., V. Schiappacasse e I. Solimano

1972/73 Padrones de poblamiento de la Quebrada de Camarones (Prov. de Tarapacá). Actas del VI Congreso de Arqueología Chilena 115-137, Santiago. 
Rappaport, L.

1990 Systems of activities and systems of settings. En Domestic Architecture and the Use of Space: An Interdisciplinary Cross-Cultural Study, editado por S. Kent, pp. 9-20. Cambridge University Press, Cambridge.

Romero, A.

2003 Chullpas de barro, interacción y dinámica política en la precordillera de Arica durante el período Intermedio Tardío. Textos Antropológicos 14:83-104.

Ruiz, M. y M. Albeck

1997 El fenómeno pukara visto desde la puna Juneña. Cuadernos 9:233-256. Universidad Nacional de Jujuy.
Stanish, C.

1989 Tamaño y complejidad de los asentamientos nucleares de Tiwanaku. En La Tecnología y Organización de la Producción Agrícola en el Estado de Tiwanaku, editado por A.L. Kolata, pp. 41-57. Editorial Sui Generis, La Paz.

Wilk, R. y W. Ashmore, editores 1988 Household and Community in the Mesoamerican Past. University of New Mexico Press, Albuquerque.

Willey, G. y P.M. Phillips

1958 Method and Theory in American Archaeology. University of Chicago Presss, Chicago.

Williams, P., J. Isla y D.J. Nash

2001 Cerro Baúl: un enclave Wari en interacción con Tiwanaku. Boletín de Arqueología PUCP 5:69-87.

\section{Notas}

1 Denominación dada por los lugareños de Chapiquiña y El Laco.
2 Base que sobresale del muro, produciendo un sobrecimiento. 